\title{
Dynamics of fine particles in liquid-solid fluidized beds
}

\author{
Dayou Liu*, Yuanfang Fu \\ Institute of Mechanics, Chinese Academy of Sciences, Beijing 100080, China
}

Received 15 September 2006; accepted 24 August 2007

\begin{abstract}
On the basis of the Local Equilibrium Model (LEM), fine particles with large Richardson-Zaki exponent $n$ show, under certain conditions during bed expansion and collapse, different dynamic behavior from particles with small $n$. For an expansion process there may be a concentration discontinuity propagating upward from the distributor, and, on the contrary, for a collapse process there may be a progressively broadening and upward-propagating continuous transition zone instead of discontinuity. The predictions of the bed height variation and the discontinuity trace have been validated experimentally.

(C) 2007 Chinese Society of Particuology and Institute of Process Engineering, Chinese Academy of Sciences. Published by Elsevier B.V. All rights reserved.
\end{abstract}

Keywords: Particulate fluidized bed; Concentration wave; Expansion process; Collapse process; Local Equilibrium Model

\section{Introduction}

In liquid-solid fluidized systems, the particles are dispersed quite uniformly and possess zero net velocity $\left(u_{\mathrm{p}}=0\right)$ when the fluidizing velocity $U$ exceeds the minimum fluidizing velocity $U_{\text {min }}$ and the system keeps in a steady-state. Various parameters in fluidized beds, e.g. voidage $\alpha_{\mathrm{f}}$, fluid velocity $u_{\mathrm{f}}$, etc., can be determined according to the Richardson-Zaki expression $U=u_{\mathrm{T}} \alpha_{\mathrm{f}}^{n}$ (Richardson \& Zaki, 1954). Slis, Willemse, and Kramers (1959) extended the Richardson-Zaki expression to the condition $u_{\mathrm{p}} \neq 0$ :

$U(t)-u_{\mathrm{p}}(t, x)=u_{\mathrm{T}} \alpha_{\mathrm{f}}^{n}(t, x)$.

Introducing Eq. (1) into solid phase continuity equation $\left(\partial \alpha_{\mathrm{p}} / \partial t\right)+\left(\partial\left(\alpha_{\mathrm{p}} u_{\mathrm{p}}\right) / \partial x\right)=0$, Slis et al. (1959) obtained the following propagation equation and the expression for velocity $V$ of the concentration wave:

$\frac{\partial \alpha_{\mathrm{p}}}{\partial t}+V\left(\alpha_{\mathrm{p}}\right) \frac{\partial \alpha_{\mathrm{p}}}{\partial x}=0$

$V=U(t)+u_{\mathrm{T}}\left[n \alpha_{\mathrm{f}}^{n-1}-(n+1) \alpha_{\mathrm{f}}^{n}\right]$.

They used the above two equations to develop a study on the transient process (expansion or collapse) in liquid-solid

\footnotetext{
* Corresponding author. Tel.: +86 1062573765 .

E-mail address: Dyliu@imech.ac.cn (D. Liu).
}

fluidized beds. Any disturbance in fluidizing velocity (e.g. from $U$ to $U+\Delta U$ ) can result in the variation of the fluidized state, traveling upward along the bed from the distributor. The transient process (transition from one state to another) comes to an end when all disturbances reach the bed surface, and therefrom a new fluidized state is achieved. Propagation velocity of any slight disturbance (infinitesimal $|\Delta U|$ ) is the same (see Eq. (3)) in any fluidized state, whether $\Delta U>0$ (slight expansion) or $\Delta U<0$ (slight collapse). For finite disturbance (which can be imagined as a series of infinitesimal disturbances with various voidages), the wave velocity $V$ is not constant but a function of local voidage $\alpha_{\mathrm{f}}$, and it results in chasing and interaction of waves, showing the non-linear feature of Eq. (2) and providing a source of different propagation properties between expansion and collapse with finite intensity. Slis et al. (1959) utilized Eqs. (1)-(3) to calculate the variation of bed height with time during the process of expansion or collapse and the result is well in agreement with experiments.

After Slis et al. (1959), a number of authors (Fan, Schmitz, \& Miller, 1963; Thelen \& Ramirez, 1997; Thelen \& Ramirez, 1999; van der Wielen, Sjauw Koen Fa, Potters, \& Luyben, 1997) presented models of bed-height dynamics of liquid-solid fluidized bed. Jin (2003), Liu and Jin (2003) and Jin and Liu (2005) also deduced a generalized Richardson-Zaki expression of Eq. (1) and continuous wave equations of Eqs. (2) and (3) from their Local Equilibrium Model (LEM), which was adapted from the 


\begin{tabular}{|c|c|}
\hline \multicolumn{2}{|c|}{ Nomenclature } \\
\hline$d_{\mathrm{p}}$ & particle diameter $(\mathrm{m})$ \\
\hline$D$ & inner diameter of bed $(\mathrm{m})$ \\
\hline$h$ & bed height (m) \\
\hline$h_{0}$ & bed height at packed state $(\mathrm{m})$ \\
\hline$n$ & Richardson-Zaki exponent \\
\hline$t$ & time $(\mathrm{s})$ \\
\hline$t_{\mathrm{b}}$ & $\begin{array}{l}\text { time the transition zone just arrives at bed surface } \\
\text { (s) }\end{array}$ \\
\hline$t_{\mathrm{e}}$ & $\begin{array}{l}\text { time the transition zone entirely pass through bed } \\
\text { surface }(s)\end{array}$ \\
\hline$u_{\mathrm{f}}$ & actual velocity of fluid phase (m/s) \\
\hline & actual velocity of solid phase $(\mathrm{m} / \mathrm{s})$ \\
\hline$u_{\mathrm{T}}$ & particle settling velocity $(\mathrm{m} / \mathrm{s})$ \\
\hline$U$ & fluidizing velocity (m/s) \\
\hline$U_{\min }$ & minimum fluidizing velocity $(\mathrm{m} / \mathrm{s})$ \\
\hline$V$ & velocity of the concentration wave $(\mathrm{m} / \mathrm{s})$ \\
\hline$V_{\max }$ & maximum concentration wave velocity $(\mathrm{m} / \mathrm{s})$ \\
\hline$V_{\mathrm{S}}$ & velocity of concentration shock $(\mathrm{m} / \mathrm{s})$ \\
\hline$x$ & height coordinate $(\mathrm{m})$ \\
\hline$x_{\mathrm{S}}$ & displacement of concentration shock (m) \\
\hline \multicolumn{2}{|c|}{ Greek letters } \\
\hline$\alpha_{\mathrm{f}}$ & voidage (fluid volume fraction) \\
\hline$\alpha_{\mathrm{f}, \mathrm{cr}}$ & voidage corresponding to maximal wave velocity \\
\hline$\alpha_{\mathrm{f}, \text { mid }}$ & voidage determined by Eq. (8) or (9) \\
\hline & particle volume fraction (particle concentration) \\
\hline$\alpha_{\mathrm{p}, \mathrm{c}}$ & packed particle volume fraction \\
\hline$\rho_{\mathrm{f}}$ & fluid density $\left(\mathrm{kg} / \mathrm{m}^{3}\right)$ \\
\hline$\rho_{\mathrm{p}}$ & material density of particle $\left(\mathrm{kg} / \mathrm{m}^{3}\right)$ \\
\hline \multicolumn{2}{|c|}{ Subscripts } \\
\hline B & after discontinuity \\
\hline $\mathrm{F}$ & before discontinuity \\
\hline h & bed surface \\
\hline 1 & correspond to $U_{1}$ \\
\hline 2 & correspond to $U_{2}$ \\
\hline
\end{tabular}

Two-Fluid Model by ignoring the inertia difference between the two phases, and discussed the application scope of the approximation. Using LEM, we can study the transient process in a bed with arbitrarily changing velocity $U(t)$ (e.g. rectangular or sinusoidal) including the propagation and interaction of various kinds of concentration waves (e.g. shockwave and continuous wave). The periodic changes of bed height $h(t)$ and voidage distribution $\alpha_{\mathrm{f}}(t, x)$ in a bed predicted by LEM agreed well with experiments (Jin, 2003; Liu \& Jin, 2003), proving that LEM is adequately applicable to the study of transient processes in the fluidized state.

This paper studies expansion or collapse process of liquid-solid fluidized bed under the condition that the fluidizing velocity stepwise increases from $U_{1}$ to $U_{2}$ or decreases from $U_{2}$ to $U_{1}$, where $U_{\min }<U_{1}<U_{2} . \alpha_{\mathrm{f} 1}$ and $\alpha_{\mathrm{f} 2}$ represent the voidages corresponding to the fluidizing velocity $U_{1}$ and $U_{2}$, respectively according to the Richardson-Zaki expression and $\left(1-\alpha_{\mathrm{p}, \mathrm{c}}\right)<\alpha_{\mathrm{f} 1}<\alpha_{\mathrm{f} 2}$ always holds.

\section{Influence of Richardson-Zaki exponent $\boldsymbol{n}$ on the critical voidage $\alpha_{f, c r}$}

Based on Eq. (3), the wave velocity $V$ reaches its maximum, $V_{\max }$, when $\alpha_{\mathrm{f}}=(n-1) /(n+1)$, for given values of $U, u_{\mathrm{T}}$ and $n$. Slis et al. (1959) and Jin (2003) used larger particles (glass beads with $d_{\mathrm{p}}=3 \mathrm{~mm}$ and $1.8 \mathrm{~mm}$, respectively), having smaller Richardson-Zaki exponents $n(n \approx 2.37$ and 2.414, respectively), and the maximum wave velocity appeared at the critical values of $\alpha_{\mathrm{f}}=\alpha_{\mathrm{f}, \mathrm{cr}}=0.407$ and 0.414 for the two kinds of particles, respectively. Both are very close to the voidage corresponding to the packed particle volume fraction $\alpha_{\mathrm{p}, \mathrm{c}}$ (about 0.6) (see Fig. 1). So expansion and collapse of the bed almost always met $\alpha_{\mathrm{f}, \mathrm{cr}}<\alpha_{\mathrm{f} 1}<\alpha_{\mathrm{f} 2}$ and the wave velocity $V$ was almost a monotonically decreasing function of voidage $\alpha_{\mathrm{f}}$ in the fluidized bed. In this case (larger particles), we always see a concentration discontinuity propagating upward from the distributor when the bed collapses and a progressively broadening and upward-propagating continuous transition zone (between the upper dense phase and the lower dilute phase) when the bed expands.

When Richardson-Zaki exponent $n$ is large (corresponding to small particle diameter $d_{\mathrm{p}}$ or smaller density difference $\left.\left(\rho_{\mathrm{p}}-\rho_{\mathrm{f}}\right)\right)$, the critical value of voidage $\alpha_{\mathrm{f}, \mathrm{cr}}$, corresponding to the maximum wave velocity $V_{\max }$, is large. Therefore, fluidization with $\alpha_{\mathrm{f}}<\alpha_{\mathrm{f} \text {,cr }}$ may take place in the bed. In this case, the wave velocity will increase as the voidage increases (see Fig. 1). If $\alpha_{\mathrm{f} 1}$ and $\alpha_{\mathrm{f} 2}$ satisfy $\alpha_{\mathrm{f} 1}<\alpha_{\mathrm{f} 2}<\alpha_{\mathrm{f}, \mathrm{cr}}$ or $\alpha_{\mathrm{f} 1}<\alpha_{\mathrm{f}, \mathrm{cr}}<\alpha_{\mathrm{f} 2}$, the phenomena in expansion and collapse processes of these particles are quite different from those for larger particles. For example, we may see a concentration discontinuity not in the collapse process but in the expansion process when $\alpha_{\mathrm{f} 1}<\alpha_{\mathrm{f} 2}<\alpha_{\mathrm{f}, \mathrm{cr}}$.

In a process of expansion or collapse, between the uniform upper zone (dense phase when expanding or dilute phase when collapsing) and uniform lower zone, there is always a transition zone with the voidage monotonically changing along the

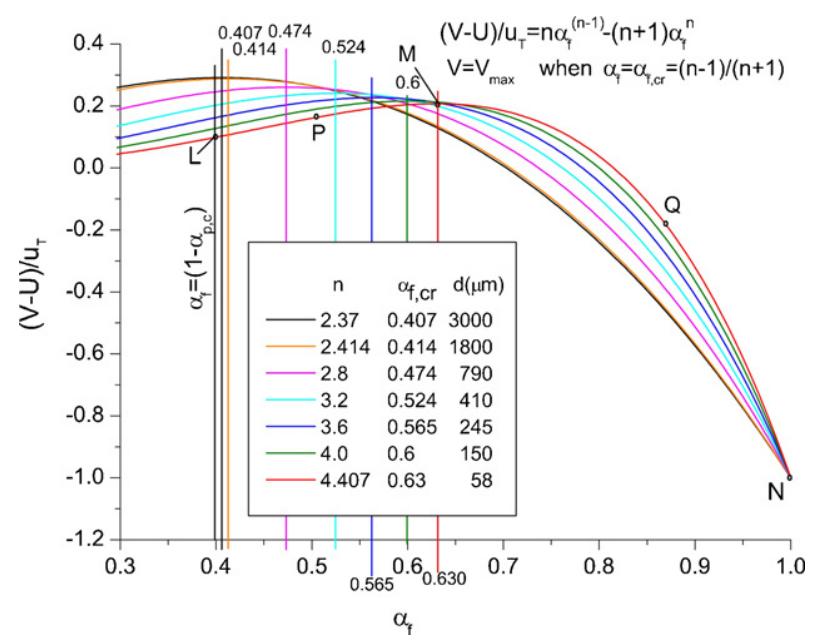

Fig. 1. Relation between voidage and relative wave velocity for various $n$. 
bed height. The transition zone will get wider and wider when the wave velocities in the transition zone increase monotonically from the bottom up, otherwise the transition zone will get narrower and narrower and finally form a concentration discontinuity (concentration shockwave) when the wave velocities in the zone decrease monotonically from the bottom up. Therefore, the shockwave velocity $V_{\mathrm{s}}$ must be greater than the velocity of continuous wave before the shockwave, $V\left(t, \alpha_{\mathrm{f}, \mathrm{F}}\right)$, and less than the velocity of continuous wave after the shockwave, $V\left(t, \alpha_{\mathrm{f}, \mathrm{B}}\right)$ (see Eq. (5) below).

Through mass conservation of the solid phase across the shockwave plane, the shockwave velocity $V_{\mathrm{s}}$ can be expressed as (Jin, 2003; Jin \& Liu, 2005; Liu \& Jin, 2003):

$$
\begin{aligned}
& V_{\mathrm{s}}\left(t, \alpha_{\mathrm{f}, \mathrm{F}}, \alpha_{\mathrm{f}, \mathrm{B}}\right)=\frac{\alpha_{\mathrm{p}, \mathrm{B}} u_{\mathrm{p}, \mathrm{B}}-\alpha_{\mathrm{p}, \mathrm{F}} u_{\mathrm{p}, \mathrm{F}}}{\alpha_{\mathrm{p}, \mathrm{B}}-\alpha_{\mathrm{p}, \mathrm{F}}} \\
& =U(t)+u_{\mathrm{T}} \frac{\alpha_{\mathrm{f}, \mathrm{B}}^{n}\left(1-\alpha_{\mathrm{f}, \mathrm{B}}\right)-\alpha_{\mathrm{f}, \mathrm{F}}^{n}\left(1-\alpha_{\mathrm{f}, \mathrm{F}}\right)}{\alpha_{\mathrm{f}, \mathrm{B}}-\alpha_{\mathrm{f}, \mathrm{F}}}
\end{aligned}
$$

$V\left(t, \alpha_{\mathrm{f}, \mathrm{F}}\right)<V_{\mathrm{s}}\left(t, \alpha_{\mathrm{f}, \mathrm{F}}, \alpha_{\mathrm{f}, \mathrm{B}}\right)<V\left(t, \alpha_{\mathrm{f}, \mathrm{B}}\right)$,

where $\alpha_{\mathrm{p}, \mathrm{F}}$ and $\alpha_{\mathrm{p}, \mathrm{B}}, \alpha_{\mathrm{f}, \mathrm{F}}$ and $\alpha_{\mathrm{f}, \mathrm{B}}, u_{\mathrm{p}, \mathrm{F}}$ and $u_{\mathrm{p}, \mathrm{B}}$ represent the particle concentration, voidage and particle velocity before and after the shockwave, respectively.

\section{Partitioning of $\alpha_{\mathrm{f} 2}-\alpha_{\mathrm{f} 1}$ plane}

For given values of Richardson-Zaki exponent $n$ and packed particle volume fraction $\alpha_{\mathrm{p}, \mathrm{c}}$, the $\alpha_{\mathrm{f} 2}-\alpha_{\mathrm{f} 1}$ plane can be partitioned, according to the numerical relation among $\alpha_{\mathrm{f} 1}, \alpha_{\mathrm{f} 2}$ and $\alpha_{\mathrm{f}, \mathrm{cr}}$, into four regions, i.e. region I through region IV, as shown in Fig. 2. In each region, the relation between wave velocity $V$ and voidage $\alpha_{\mathrm{f}}$ possesses a distinct character, as a result, the properties of the transition zone between uniform upper and lower zones in a transient process are quite different. The ordinate $\alpha_{\mathrm{f} 1}$ in Fig. 2 is the voidage of dense phase (i.e. the voidage in upper zone when expanding, or the voidage in lower zone when collapsing), and the abscissa $\alpha_{\mathrm{f} 2}$ is the voidage of dilute phase. The fluidizing velocities $U_{1}$ and $U_{2}$, normalized against the particle settling velocity $u_{\mathrm{T}}$, are displayed as the right and top axes, respectively in Fig. 2. The scales of these axes are specified through the formula of $U_{k} / u_{\mathrm{T}}=\alpha_{\mathrm{f}, k}^{n}(k=1$ or 2$)$. The voidage $\alpha_{\mathrm{f}}(t, x)$ at any time $t$ and any height $x$ within the transition zone is always between $\alpha_{\mathrm{f} 1}$ and $\alpha_{\mathrm{f} 2}$, i.e. $\alpha_{\mathrm{f} 1}<\alpha_{\mathrm{f}}(t, x)<\alpha_{\mathrm{f} 2}$. The coordinates of points $\mathrm{E}, \mathrm{F}, \mathrm{G}, \mathrm{H}, \mathrm{J}$ and $\mathrm{K}$ with respect to the set of $\alpha_{\mathrm{f} 2}$ and $\alpha_{\mathrm{f} 1}$ axes in Fig. 2 are $(1,1),\left(\alpha_{\mathrm{f}, \mathrm{cr}}, \alpha_{\mathrm{f}, \mathrm{cr}}\right),\left(1, \alpha_{\mathrm{f}, \mathrm{cr}}\right),\left(\left(1-\alpha_{\mathrm{p}, \mathrm{c}}\right)\right.$, $\left.\left(1-\alpha_{\mathrm{p}, \mathrm{c}}\right)\right),\left(\alpha_{\mathrm{f}, \mathrm{cr}},\left(1-\alpha_{\mathrm{p}, \mathrm{c}}\right)\right)$ and $\left(1,\left(1-\alpha_{\mathrm{p}, \mathrm{c}}\right)\right)$, respectively. Except for region IV in $\alpha_{\mathrm{f} 2}-\alpha_{\mathrm{f} 1}$ plane, which will not be considered in this study because the condition of $\left(1-\alpha_{\mathrm{p}, \mathrm{c}}\right)<\alpha_{\mathrm{f} 1}<\alpha_{\mathrm{f} 2}$ is not satisfied, the other three regions will be discussed in detail below.

\subsection{Region I characterized by $\left(1-\alpha_{p, c}\right)<\alpha_{f, c r}<\alpha_{f 1}<\alpha_{f 2}$}

Every point within the triangle EFG labeled region I meets the condition of $\alpha_{\mathrm{f}, \mathrm{cr}}<\alpha_{\mathrm{f} 1}<\alpha_{\mathrm{f}}(t, x)<\alpha_{\mathrm{f} 2}$. Under this condition,

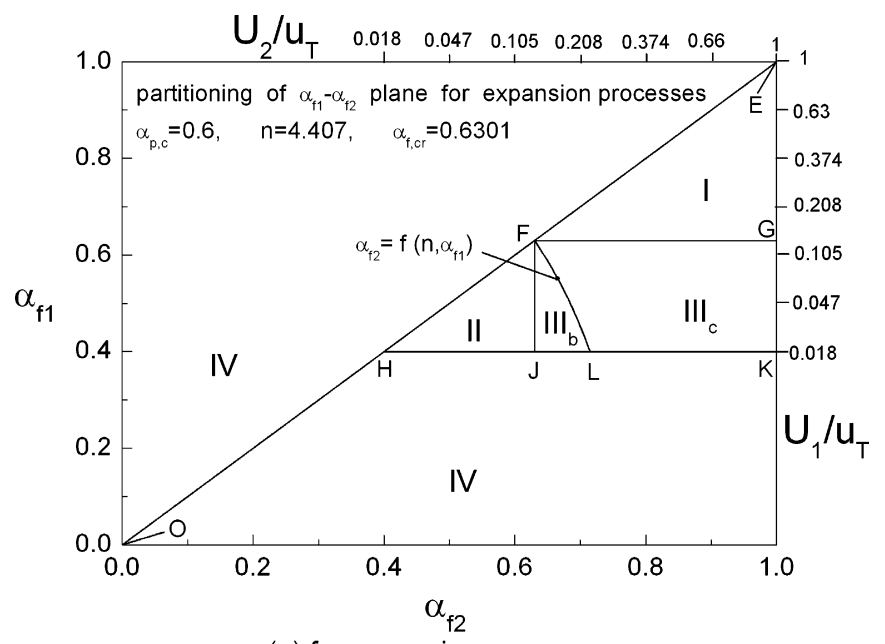

(a) for expansion processes



(b) for collapse processes

Fig. 2. The $\alpha_{\mathrm{f} 2}-\alpha_{\mathrm{f} 1}$ plane divided according to relative magnitudes of $\alpha_{\mathrm{f} 1}, \alpha_{\mathrm{f} 2}$ and $\alpha_{\mathrm{f}, \mathrm{cr}}$ for given value of $n$.

the wave velocity $V$ is a monotonically decreasing function of voidage $\alpha_{\mathrm{f}}$ (as exemplified by the segment MN on curve LPMQN in Fig. 1).

\subsubsection{Bed expansion}

In this case, the wave velocity is increasing monotonically along the height in the transition zone between upper dense phase $\left(\alpha_{\mathrm{f}}=\alpha_{\mathrm{f} 1}\right)$ and lower dilute phase $\left(\alpha_{\mathrm{f}}=\alpha_{\mathrm{f} 2}\right)$ since voidages decrease monotonically along the height and the wave velocity is a monotonically decreasing function of voidage. As a result, the transition zone gets wider and wider. This is the expansion process as we have already known.

\subsubsection{Bed collapse}

In this case, the wave velocity is decreasing monotonically along the height since voidages increase monotonically along the height and the wave velocity is a monotonically decreasing function of voidage. As a result, the transition zone (even if with a certain width initially) gets narrower and narrower and finally forms a concentration discontinuity. This is also the already wellknown collapse process. According to Eq. (4), the velocity of 
the discontinuity plane is

$V_{\mathrm{S}}=U_{1}+u_{\mathrm{T}} \frac{\alpha_{\mathrm{f} 1}^{n}\left(1-\alpha_{\mathrm{f} 1}\right)-\alpha_{\mathrm{f} 2}^{n}\left(1-\alpha_{\mathrm{f} 2}\right)}{\alpha_{\mathrm{f} 1}-\alpha_{\mathrm{f} 2}}$.

\subsection{Region II characterized by $\left(1-\alpha_{p, c}\right)<\alpha_{f 1}<\alpha_{f 2}<\alpha_{f, c r}$}

Every point in the triangle FHJ labeled region II meets the condition of $\left(1-\alpha_{\mathrm{p}, \mathrm{c}}\right)<\alpha_{\mathrm{f} 1}<\alpha_{\mathrm{f}}(t, x)<\alpha_{\mathrm{f} 2}<\alpha_{\mathrm{f}, \mathrm{cr}}$. Under this condition, the wave velocity is a monotonically increasing function of voidage (as exemplified by the segment LM on curve LPMQN in Fig. 1). It can be concluded from an analogous analysis that there is no concentration discontinuity but a progressively broadening and upward-propagating continuous transition zone when collapsing. On the contrary, there is a concentration discontinuity between the upper dense phase and lower dilute phase when expanding. According to Eq. (4), the velocity of the discontinuity plane is

$V_{\mathrm{S}}=U_{2}+u_{\mathrm{T}} \frac{\alpha_{\mathrm{f} 2}^{n}\left(1-\alpha_{\mathrm{f} 2}\right)-\alpha_{\mathrm{f} 1}^{n}\left(1-\alpha_{\mathrm{f} 1}\right)}{\alpha_{\mathrm{f} 2}-\alpha_{\mathrm{f} 1}}$.

\subsection{Region III characterized by $\left(1-\alpha_{p, c}\right)<\alpha_{f 1}<\alpha_{f, c r}<\alpha_{f 2}$}

Every point in the rectangle FJKG labeled region III meets the condition of $\left(1-\alpha_{\mathrm{p}, \mathrm{c}}\right)<\alpha_{\mathrm{f} 1}<\alpha_{\mathrm{f}, \mathrm{cr}}<\alpha_{\mathrm{f}}(t, x)<\alpha_{\mathrm{f} 2}$. Under this condition, the wave velocity is not a monotonic function of voidage. As exemplified by the segment PMQ on curve LPMQN in Fig. 1 with $\left.\alpha_{\mathrm{f}}\right|_{\mathrm{P}}=\alpha_{\mathrm{f} 1}$ and $\left.\alpha_{\mathrm{f}}\right|_{\mathrm{Q}}=\alpha_{\mathrm{f} 2}$, wave velocity $V$ increases monotonically with $\alpha_{\mathrm{f}}$ in the range of $\alpha_{\mathrm{f} 1}<\alpha_{\mathrm{f}}<\alpha_{\mathrm{f}, \mathrm{cr}}$ (see the segment PM in Fig. 1) and decreases monotonically with $\alpha_{\mathrm{f}}$ in the range of $\alpha_{\mathrm{f}, \mathrm{cr}}<\alpha_{\mathrm{f}}<\alpha_{\mathrm{f} 2}$ (see the segment MQ in Fig. 1). Therefore, under this condition, waves in the transition zone may exhibit complex process of chasing and overlapping. The following analysis shows that there is always a concentration discontinuity in the transition zone, no matter in expansion or collapse. Besides, there may also exist a series of concentration waves behind the discontinuity.

\subsubsection{Bed expansion}

In this case, dilute phase $\alpha_{\mathrm{f} 2}$ is behind dense phase $\alpha_{\mathrm{f} 1}$. The voidage in the transition zone decreases monotonically from the bottom up, but the wave velocity does not change monotonically. Somewhere in the transition zone there may be a layer with the fastest wave velocity. When the wave with fastest propagating velocity (referred to as wave $\mathrm{M}$ ) overtakes the previous waves, a discontinuity forms. There must be some waves after the wave $\mathrm{M}$ which can overtake the discontinuity as well because the propagating velocity of the discontinuity must be less than the fastest wave velocity (see Eq. (5)), and thus less than the velocity of some waves behind the wave $\mathrm{M}$. As a result, the discontinuity is further intensified. If $\alpha_{\mathrm{f} 2}$ is large enough, in the transition zone there will be a wave (referred to as wave $\mathrm{C}$ with the corresponding voidage named as $\alpha_{\mathrm{f}, \mathrm{mid}}$ ), behind which the waves cannot catch the discontinuity because the velocity of these waves is equal to or less than the velocity of the discontinuity. According to the condition that the wave velocity corresponding to voidage $\alpha_{\mathrm{f}, \text { mid }}$, i.e. $V\left(\alpha_{\mathrm{f}, \mathrm{mid}}\right)$, equals the discontinuity velocity $V_{\mathrm{S}}, \alpha_{\mathrm{f}, \text { mid }}$ should satisfy the following relation:

$$
\begin{aligned}
U_{2} & +u_{\mathrm{T}}\left[n \alpha_{\mathrm{f}, \text { mid }}^{n-1}-(n+1) \alpha_{\mathrm{f}, \text { mid }}^{n}\right] \\
& =U_{2}+u_{\mathrm{T}} \frac{\alpha_{\mathrm{f}, \text { mid }}^{n}\left(1-\alpha_{\mathrm{f}, \mathrm{mid}}\right)-\alpha_{\mathrm{f} 1}^{n}\left(1-\alpha_{\mathrm{f} 1}\right)}{\alpha_{\mathrm{f}, \text { mid }}-\alpha_{\mathrm{f} 1}} .
\end{aligned}
$$

The above equation shows that $\alpha_{\mathrm{f} \text {,mid }}$ is just a function of $n$ and $\alpha_{\mathrm{f} 1}$ and can thus be written as $\alpha_{\mathrm{f}, \mathrm{mid}}=f\left(n, \alpha_{\mathrm{f} 1}\right)$. And now, the whole transition zone consists of a concentration discontinuity abruptly from $\alpha_{\mathrm{f} 1}$ to $\alpha_{\mathrm{f}, \mathrm{mid}}$, followed by a continuous transition from $\alpha_{\mathrm{f} \text {,mid }}$ to $\alpha_{\mathrm{f} 2}$. If $\alpha_{\mathrm{f} 2}<\alpha_{\mathrm{f} \text {,mid }}$ (that is, $\alpha_{\mathrm{f} 2}$ is not so large), then the discontinuity encompasses all waves in the transition zone from $\alpha_{\mathrm{f} 1}$ to $\alpha_{\mathrm{f} 2}$ without continuous waves following it.

Therefore, as shown in Fig. 2(a), the whole region III can be divided into two subregions, subregion III $_{c}$ and subregion $\mathrm{III}_{\mathrm{b}}$. Subregion $\mathrm{III}_{\mathrm{b}}$ covers the range of $\left(1-\alpha_{\mathrm{p}, \mathrm{c}}\right)<\alpha_{\mathrm{f} 1}<\alpha_{\mathrm{f}, \mathrm{cr}}<\alpha_{\mathrm{f} 2}<f\left(n, \alpha_{\mathrm{f} 1}\right)$. When voidages of $\alpha_{\mathrm{f} 1}$ and $\alpha_{\mathrm{f} 2}$ fall into this range, the transition zone degenerates into a discontinuity only. Subregion $\mathrm{III}_{\mathrm{c}}$ spans the range of $\left(1-\alpha_{\mathrm{p}, \mathrm{c}}\right)<\alpha_{\mathrm{f} 1}<\alpha_{\mathrm{f}, \mathrm{cr}}<f\left(n, \alpha_{\mathrm{f} 1}\right)<\alpha_{\mathrm{f} 2}$. When voidages of $\alpha_{\mathrm{f} 1}$ and $\alpha_{\mathrm{f} 2}$ fall into this range, the transition zone consists of a discontinuity followed by a series of continuous waves.

\subsubsection{Bed collapse}

In this case, dense phase $\alpha_{\mathrm{f} 1}$ is behind dilute phase $\alpha_{\mathrm{f} 2}$. The voidage in the transition zone increases monotonically from the bottom up, but the wave velocity does not change monotonically. All the waves before the wave $\mathrm{M}$ (with the fastest wave velocity) and some waves after it are packed into a discontinuity. If $\alpha_{\mathrm{f} 1}$ is small enough, there will be a wave (referred to as wave $\mathrm{C}$ with the corresponding voidage named as $\alpha_{\mathrm{f}, \mathrm{mid}}$ ), behind which the waves cannot catch the discontinuity. According to the condition that the wave velocity corresponding to voidage $\alpha_{\mathrm{f} \text {,mid }}$ equals the discontinuity velocity, $\alpha_{\mathrm{f} \text {,mid }}$ should satisfy the following relation:

$$
\begin{aligned}
U_{1} & +u_{\mathrm{T}}\left[n \alpha_{\mathrm{f}, \text { mid }}^{n-1}-(n+1) \alpha_{\mathrm{f}, \text { mid }}^{n}\right] \\
& =U_{1}+u_{\mathrm{T}} \frac{\alpha_{\mathrm{f}, \text { mid }}^{n}\left(1-\alpha_{\mathrm{f}, \text { mid }}\right)-\alpha_{\mathrm{f} 2}^{n}\left(1-\alpha_{\mathrm{f} 2}\right)}{\alpha_{\mathrm{f}, \text { mid }}-\alpha_{\mathrm{f} 2}} .
\end{aligned}
$$

The above equation shows that $\alpha_{\mathrm{f} \text {,mid }}$ can be written as $\alpha_{\mathrm{f}, \text { mid }}=f\left(n, \alpha_{\mathrm{f} 2}\right)$. And now, the whole transition zone consists of a discontinuity from $\alpha_{\mathrm{f} 2}$ to $\alpha_{\mathrm{f} \text {,mid }}$ followed by a continuous transition from $\alpha_{\mathrm{f} \text {,mid }}$ to $\alpha_{\mathrm{f} 1}$. If $\alpha_{\mathrm{f} 1}>\alpha_{\mathrm{f} \text {,mid }}$ (that is, $\alpha_{\mathrm{f} 1}$ is not so small), then the discontinuity encompasses all waves in the transition zone from $\alpha_{\mathrm{f} 2}$ to $\alpha_{\mathrm{f} 1}$ without continuous waves following it.

Therefore, as shown in Fig. 2(b), the whole region III can also be divided into two subregions, subregion $\mathrm{III}_{\mathrm{c}}$ and subregion $\mathrm{III}_{\mathrm{b}}$. Subregion $\mathrm{III}_{\mathrm{b}}$ covers the range of $\left(1-\alpha_{\mathrm{p}, \mathrm{c}}\right)<f(n$, $\left.\alpha_{\mathrm{f} 2}\right)<\alpha_{\mathrm{f} 1}<\alpha_{\mathrm{f}, \mathrm{cr}}<\alpha_{\mathrm{f} 2}$. When voidages of $\alpha_{\mathrm{f} 2}$ and $\alpha_{\mathrm{f} 1}$ fall into this range, the transition zone degenerates into a discontinuity only. Subregion III $_{\mathrm{c}}$ spans the range of $\left(1-\alpha_{\mathrm{p}, \mathrm{c}}\right)<\alpha_{\mathrm{f} 1}<f(n$, $\left.\alpha_{\mathrm{f} 2}\right)<\alpha_{\mathrm{f}, \mathrm{cr}}<\alpha_{\mathrm{f} 2}$. When voidages of $\alpha_{\mathrm{f} 1}$ and $\alpha_{\mathrm{f} 2}$ fall into this range, the transition zone consists of a discontinuity followed by a series of continuous waves. 


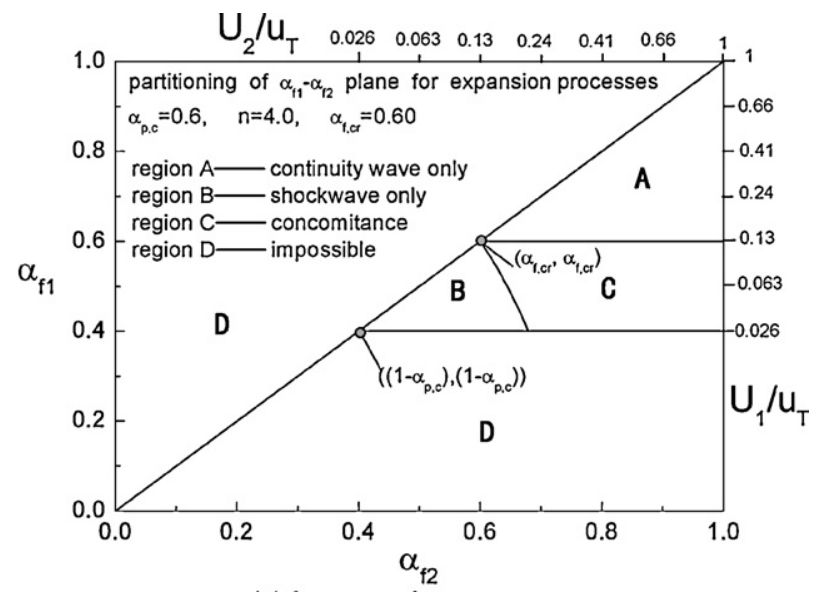

(a) for expansion processes

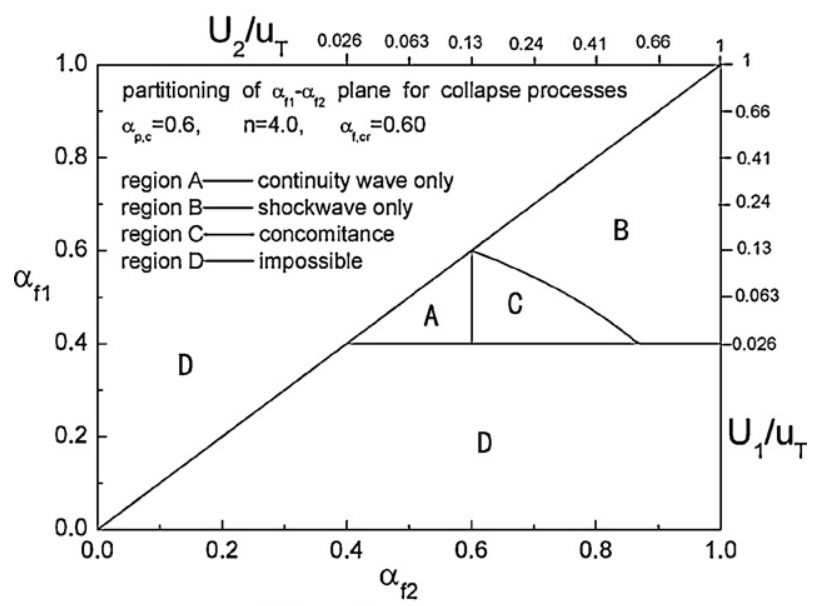

(b) for collapse processes

Fig. 3. The $\alpha_{\mathrm{f} 2}-\alpha_{\mathrm{f} 1}$ plane divided according to the characteristics of transition zone for $n=4.0$.

Plane $\alpha_{\mathrm{f} 2}-\alpha_{\mathrm{f} 1}$ can now be re-divided into four regions, i.e. $\mathrm{A}, \mathrm{B}, \mathrm{C}$ and $\mathrm{D}$, according to whether the transition zone has a discontinuity (shockwave) or continuous waves (see Fig. 3(a) and (b)). For the parameter combination $\left(\alpha_{\mathrm{f} 2}, \alpha_{\mathrm{f} 1}\right)$ in Region $\mathrm{A}$, there are a series of continuous waves in the transition zone without shockwave. For Region B, there is a shockwave only in the transition zone without continuous waves. For Region C, there is a shockwave followed by a series of continuous waves in the transition zone. Corresponding to the Regions $\mathrm{A}, \mathrm{B}$ and $\mathrm{C}$, the transition zones are named types $\mathrm{A}$, $\mathrm{B}$ and $\mathrm{C}$.

For expansion processes, Region $\mathrm{A}, \mathrm{C}$ and $\mathrm{D}$ are just the region $\mathrm{I}$, subregion $\mathrm{III}_{\mathrm{c}}$ and region $\mathrm{IV}$, respectively, as mentioned above, and Region B consists of the region II and subregion $\mathrm{III}_{\mathrm{b}}$ (see Fig. 3(a)). For collapse processes, Region A, C and D are just the region II, subregion $\mathrm{III}_{\mathrm{c}}$ and region IV, respectively, and Region B consists of the region I and subregion $\mathrm{III}_{\mathrm{b}}$ (see Fig. 3(b)).

For $n=2.414$, the regions in plane $\alpha_{\mathrm{f} 2}-\alpha_{\mathrm{f} 1}$ are shown in Fig. 4(a, expansion) and (b, collapse). It can be seen obviously from Fig. 4(a) and (b) that almost only Region A for expansion and Region B for collapse are likely to occur.



(a) for expansion processes

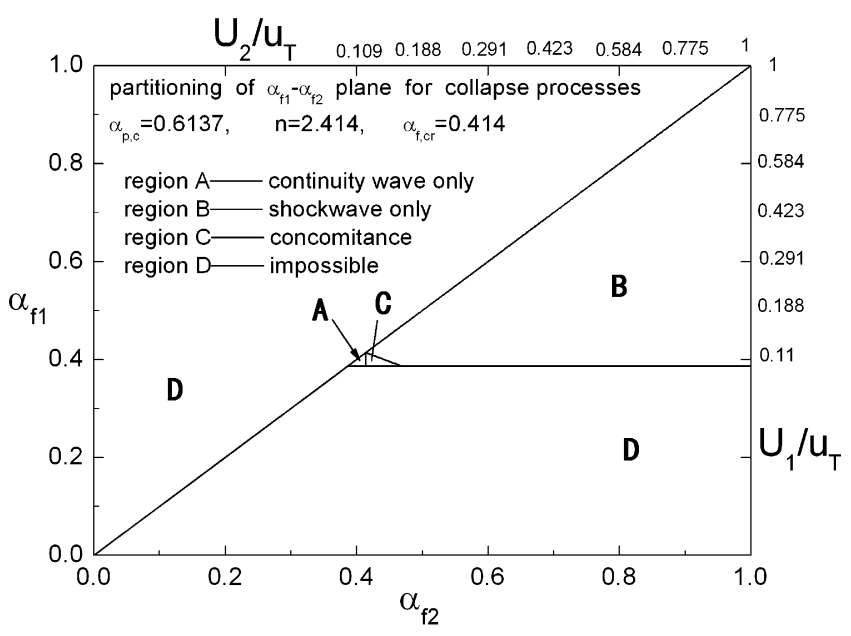

(b) for collapse processes

Fig. 4. The $\alpha_{\mathrm{f} 2}-\alpha_{\mathrm{f} 1}$ plane divided according to the characteristics of transition zone for $n=2.414$.

\section{Variation of the bed height $h(t)$ and bed surface velocity $\mathrm{d} h / \mathrm{d} t$}

Suppose $t_{\mathrm{b}}$ is the time when the front of transition zone just arrives at bed surface, before which $\left(0<t<t_{\mathrm{b}}\right)$ the bed surface goes up (when expanding) or down (when collapsing) with a constant velocity $\pm\left(U_{2}-U_{1}\right)$, and $t_{\mathrm{e}}$ is the time when the tail of transition zone passes through bed surface, after which $\left(t>t_{\mathrm{e}}\right)$ the bed height stops varying and the transient process comes to the end. If the transition zone degenerates into a discontinuity, then $t_{\mathrm{b}}=t_{\mathrm{e}}$.

\subsection{Expansion process \\ $\left(\left.U\right|_{t<0}=U_{1},\left.\quad U\right|_{t>0}=U_{2},\left.\quad h\right|_{t \leq 0}=h_{1},\left.\quad h\right|_{t \geq t_{e}}=h_{2}\right)$}

Applying Eq. (1) to bed surface $(x=h(t))$, we obtain $\mathrm{d} h / \mathrm{d} t=u_{\mathrm{p}, \mathrm{h}}(t)=U_{2}-u_{\mathrm{T}} \alpha_{\mathrm{f}, \mathrm{h}}^{n}(t)$ where the voidage and solid phase velocity at bed surface are defined as $\alpha_{\mathrm{f}, \mathrm{h}}(t)=\alpha_{\mathrm{f}}(t$, $x)\left.\right|_{x=\mathrm{h}}$ and $u_{\mathrm{p}, \mathrm{h}}(t)=\left.u_{\mathrm{p}}(t, x)\right|_{x=\mathrm{h}}$, respectively. In the interval of $0<t<t_{\mathrm{b}}, \mathrm{d} h / \mathrm{d} t=u_{\mathrm{p}, \mathrm{h}}=U_{2}-U_{1}$ because $\alpha_{\mathrm{f}, \mathrm{h}}(t)=\alpha_{\mathrm{f} 1}$. When $t>t_{\mathrm{e}}, \mathrm{d} h / \mathrm{d} t=u_{\mathrm{p}, \mathrm{h}}=0$ because $\alpha_{\mathrm{f}, \mathrm{h}}(t)=\alpha_{\mathrm{f} 2}$. In the interval of 
$t_{\mathrm{b}}<t<t_{\mathrm{e}}$ when the transition zone of type A passes through the bed surface, the voidage $\alpha_{\mathrm{f}, \mathrm{h}}(t)$ changes continuously from $\alpha_{\mathrm{f} 1}$ to $\alpha_{\mathrm{f} 2}$ and so the solid phase velocity $u_{\mathrm{p}, \mathrm{h}}(t)$, i.e. the bed surface velocity $\mathrm{d} h / \mathrm{d} t$, changes continuously from $\left(U_{2}-U_{1}\right)$ to zero and the bed height curve $h(t)$ is smooth. When the transition zone of type B passes through the bed surface, the voidage $\alpha_{\mathrm{f}, \mathrm{h}}(t)$ jumps from $\alpha_{\mathrm{f} 1}$ to $\alpha_{\mathrm{f} 2}$, and so the solid phase velocity $u_{\mathrm{p}, \mathrm{h}}(t)$ drops from $\left(U_{2}-U_{1}\right)$ to zero and the curve $h(t)$ has a sharp break at $t=t_{\mathrm{b}}=t_{\mathrm{e}}$. When the transition zone of type $\mathrm{C}$ pass through the bed surface, the voidage $\alpha_{\mathrm{f}, \mathrm{h}}(t)$ first jumps from $\alpha_{\mathrm{f} 1}$ to $\alpha_{\mathrm{f}, \mathrm{mid}}$ at the time $t=t_{\mathrm{b}}$, when the discontinuity passes through the bed surface, and then changes from $\alpha_{\mathrm{f} \text {,mid }}$ to $\alpha_{\mathrm{f} 2}$ continuously when the continuous waves following the discontinuity pass through the bed surface sequentially. Correspondingly, the solid phase velocity $u_{\mathrm{p}, \mathrm{h}}(t)$ first drops from $\left(U_{2}-U_{1}\right)$ to $\left(U_{2}-u_{\mathrm{T}} \alpha_{\mathrm{f}, \text { mid }}^{n}\right)$ at $t=t_{\mathrm{b}}$ and then changes from $\left(U_{2}-u_{\mathrm{T}} \alpha_{\mathrm{f}, \text { mid }}^{n}\right)$ to zero continuously. So the curve $h(t)$ has a moderate break at $t=t_{\mathrm{b}}$ and then changes to the terminal value $h_{2}$ smoothly. For the expansion process, $\alpha_{\mathrm{f}, \mathrm{mid}}=f\left(n, \alpha_{\mathrm{f} 1}\right)$.

The expressions of $t_{\mathrm{b}}$ and $t_{\mathrm{e}}$ are summarized in Table 1 , the formulas calculating the bed surface velocity and bed height are expressed by Eq. (10) (for Region B, the condition $\left(t_{\mathrm{b}}<t<t_{\mathrm{e}}\right.$ ) does not exist), and the typical bed height curves calculated by Eq. (10) for $n=4.0$ are shown in Fig. 5.

$$
\left\{\begin{array}{l}
\left\{\begin{array}{l}
\alpha_{\mathrm{f}, \mathrm{h}}(t)=\alpha_{\mathrm{f} 1} \\
u_{\mathrm{p}, \mathrm{h}}(t)=U_{2}-U_{1} \quad\left(0<t \leq t_{\mathrm{b}}\right) \\
h(t)=h_{1}+\left(U_{2}-U_{1}\right) t
\end{array}\right. \\
\left\{\begin{array}{l}
u_{\mathrm{p}, \mathrm{h}}\left(\alpha_{\mathrm{f}, \mathrm{h}}\right)=U_{2}-u_{\mathrm{T}} \alpha_{\mathrm{f}, \mathrm{h}}^{n} \\
h\left(\alpha_{\mathrm{f}, \mathrm{h}}\right)=\left\{U_{2}+u_{\mathrm{T}}\left[n \alpha_{\mathrm{f}, \mathrm{h}}^{n-1}-(n+1) \alpha_{\mathrm{f}, \mathrm{h}}^{n}\right]\right\} t\left(\alpha_{\mathrm{f}, \mathrm{h}}\right) \quad\left(t_{\mathrm{b}}<t<t_{\mathrm{e}}\right) \\
t\left(\alpha_{\mathrm{f}, \mathrm{h}}\right)=\left[h_{1}\left(1-\alpha_{\mathrm{f} 1}\right)\right] /\left[n u_{\mathrm{T}} \alpha_{\mathrm{f}, \mathrm{h}}^{n-1}\left(1-\alpha_{\mathrm{f}, \mathrm{h}}\right)^{2}\right]
\end{array}\right. \\
\left\{\begin{array}{l}
\alpha_{\mathrm{f}, \mathrm{h}}(t)=\alpha_{\mathrm{f} 2} \\
u_{\mathrm{p}, \mathrm{h}}(t)=0 \\
h(t)=h_{2}=h_{1}\left(1-\alpha_{\mathrm{f} 1}\right) /\left(1-\alpha_{\mathrm{f} 2}\right)
\end{array}\right.
\end{array}\right.
$$

\subsection{Collapse process}

$\left(\left.U\right|_{t<0}=U_{2},\left.\quad U\right|_{t>0}=U_{1},\left.\quad h\right|_{t \leq 0}=h_{2},\left.\quad h\right|_{t \geq t_{e}}=h_{1}\right)$

Applying Eq. (1) to bed surface, we obtain $\mathrm{d} h / \mathrm{d} t=u_{\mathrm{p}, \mathrm{h}}(t)=U_{1}-u_{\mathrm{T}} \alpha_{\mathrm{f}, \mathrm{h}}^{n}(t)$. In the interval of $0<t<t_{\mathrm{b}}$, $\mathrm{d} h / \mathrm{d} t=u_{\mathrm{p}, \mathrm{h}}=-\left(U_{2}-U_{1}\right)$ because $\alpha_{\mathrm{f}, \mathrm{h}}(t)=\alpha_{\mathrm{f} 2}$. When $t>t_{\mathrm{e}}$, $\mathrm{d} h / \mathrm{d} t=u_{\mathrm{p}, \mathrm{h}}=0$ because $\alpha_{\mathrm{f}, \mathrm{h}}(t)=\alpha_{\mathrm{f} 1}$. The voidage $\alpha_{\mathrm{f}}$ in the transition zone of type A changes continuously from $\alpha_{\mathrm{f} 2}$ to $\alpha_{\mathrm{f} 1}$, so the bed height curve $h(t)$ is smooth. The transition zone of type B degenerates into a discontinuity, so the curve $h(t)$ has a sharp break. The transition zone of type $\mathrm{C}$ consists of a discontinuity followed by a series of continuous waves, so the curve $h(t)$ has a moderate break at $t=t_{\mathrm{b}}$ and then changes to the terminal value $h_{1}$ smoothly. For the expansion process, $\alpha_{\mathrm{f}, \mathrm{mid}}=f\left(n, \alpha_{\mathrm{f} 2}\right)$.

The expressions of $t_{\mathrm{b}}$ and $t_{\mathrm{e}}$ are summarized in Table 2, the formulas calculating the bed surface velocity and bed height in collapse process are expressed by Eq. (11) (for Region B, the condition $\left(t_{\mathrm{b}}<t<t_{\mathrm{e}}\right)$ does not exist), and the typical bed height curves using Eq. (11) for $n=4.0$ are shown in Fig. 6.

$$
\left\{\begin{array}{l}
\left\{\begin{array}{l}
\alpha_{\mathrm{f}, \mathrm{h}}(t)=\alpha_{\mathrm{f} 2} \\
u_{\mathrm{p}, \mathrm{h}}(t)=-\left(U_{2}-U_{1}\right) \quad\left(0<t \leq t_{\mathrm{b}}\right) \\
h(t)=h_{2}-\left(U_{2}-U_{1}\right) t
\end{array}\right. \\
\left\{\begin{array}{l}
u_{\mathrm{p}, \mathrm{h}}\left(\alpha_{\mathrm{f}, \mathrm{h}}\right)=U_{1}-u_{\mathrm{T}} \alpha_{\mathrm{f}, \mathrm{h}}^{n} \\
h\left(\alpha_{\mathrm{f}, \mathrm{h}}\right)=\left\{U_{1}+u_{\mathrm{T}}\left[n \alpha_{\mathrm{f}, \mathrm{h}}^{n-1}-(n+1) \alpha_{\mathrm{f}, \mathrm{h}}^{n}\right]\right\} t\left(\alpha_{\mathrm{f}, \mathrm{h}}\right) \quad\left(t_{\mathrm{b}}<t<t_{\mathrm{e}}\right) \\
t\left(\alpha_{\mathrm{f}, \mathrm{h}}\right)=\left[h_{2}\left(1-\alpha_{\mathrm{f} 2}\right)\right] /\left[n u_{\mathrm{T}} \alpha_{\mathrm{f}, \mathrm{h}}^{n-1}\left(1-\alpha_{\mathrm{f}, \mathrm{h}}\right)^{2}\right]
\end{array}\right. \\
\left\{\begin{array}{l}
\alpha_{\mathrm{f}, \mathrm{h}}(t)=\alpha_{\mathrm{f} 1} \\
u_{\mathrm{p}, \mathrm{h}}(t)=0 \\
h(t)=h_{1}
\end{array}\right.
\end{array}\right.
$$

\section{Experimental validation}

Experiments were carried out to validate the above theoretical analysis.

\subsection{Experimental setup and procedure}

Fig. 7 shows the experimental setup, including a $2.4 \mathrm{~mm}$-id and $1.2 \mathrm{~m}$-high glass column fluidized by water introduced at its bottom through a $0.012 \mathrm{~m}$ calming section packed with glass beads, and a high-resistance sieve plate to insure essentially onedimensional flow in the bed. To conduct experiments with fine particles in a narrow fluidized bed, high-pressure $(15 \pm 0.5 \mathrm{MPa})$ nitrogen is used to press cooled boiled water from storage through control and measurement system into the fluidized bed. To eliminate the influence of adhering bubbles, particles need to be soaked in cooled boiled water with continuous stirring, and then dried and kept under vacuum for $24 \mathrm{~h}$ before use. The flow rate is measured by means of an indirect method. Since the particles are very fine and the flow rate needed is very small, it is critical to guarantee a prompt response of fluidized bed to the step change of fluidizing velocity in the experiments. Therefore a horizontal bubble gauge with the same diameter as the fluidized bed is connected directly to the outlet of fluidized bed, with an air bubble injected inside. The movement of the bubble as recorded by a digital camcorder is used to monitor the actual fluidizing velocity in the fluidized bed. The bed height and the transient distribution of the particle concentration are recorded continuously by a digital camcorder. A ruler is placed parallel with the column axis to guarantee an accuracy of bed height measurement within $\pm 1 \mathrm{~mm}$.

When the inner diameter gets smaller, the drag force on the bed wall will become more prominent. Would Eq. (1), derived by ignoring the drag force on the sidewall, be still valid for a bed with an inner diameter as small as $2.4 \mathrm{~mm}$ ? The answer is positive. Although the inner diameter of the bed is only $2.4 \mathrm{~mm}$, it is not so small relative to the particle diameter we used. Many reported experiments have shown that Eq. (1) is valid under the condition of $D: d_{\mathrm{p}}=16: 1$.

In a vertical column with an inner diameter of $D$, between two cross-sections at a separation of $\Delta z$, the drag force of the fluid on the sidewall $F_{\mathrm{f}, \mathrm{w}}$ equals $\Delta z \pi D \tau_{\mathrm{f}, \mathrm{w}}$, where the shear stress on the sidewall $\tau_{\mathrm{f}, \mathrm{w}} \propto \mu_{\mathrm{f}} U / D$ and $U$ is the superficial velocity in this section, as a result, the drag force $F_{\mathrm{f}, \mathrm{w}} \propto \Delta z \pi \mu_{\mathrm{f}} U$. The gravity 
(a)
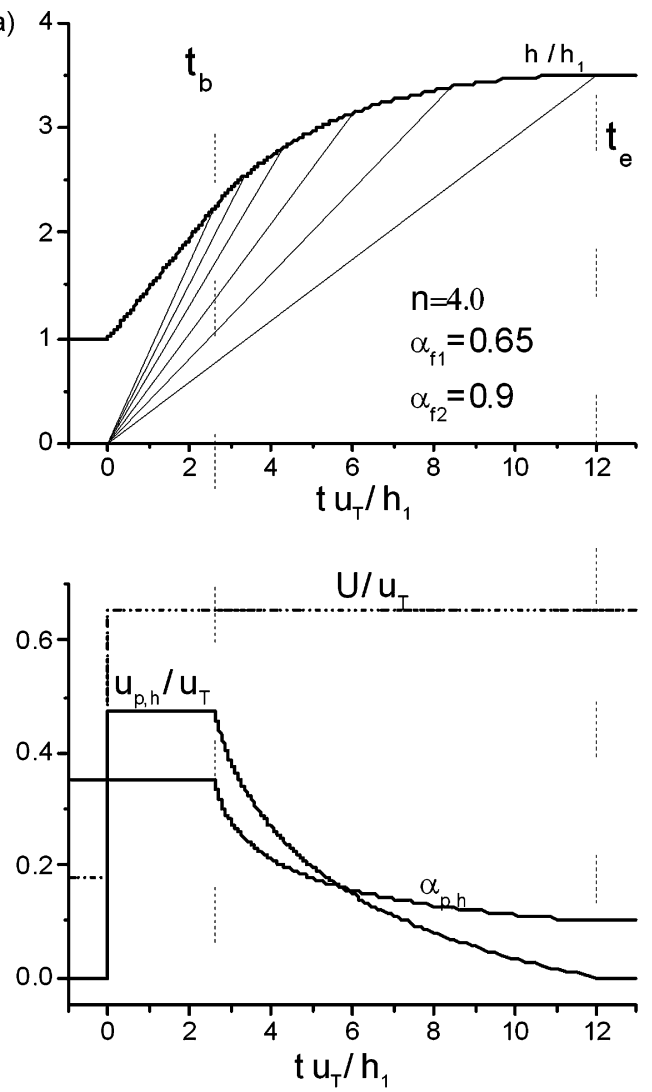

(b)
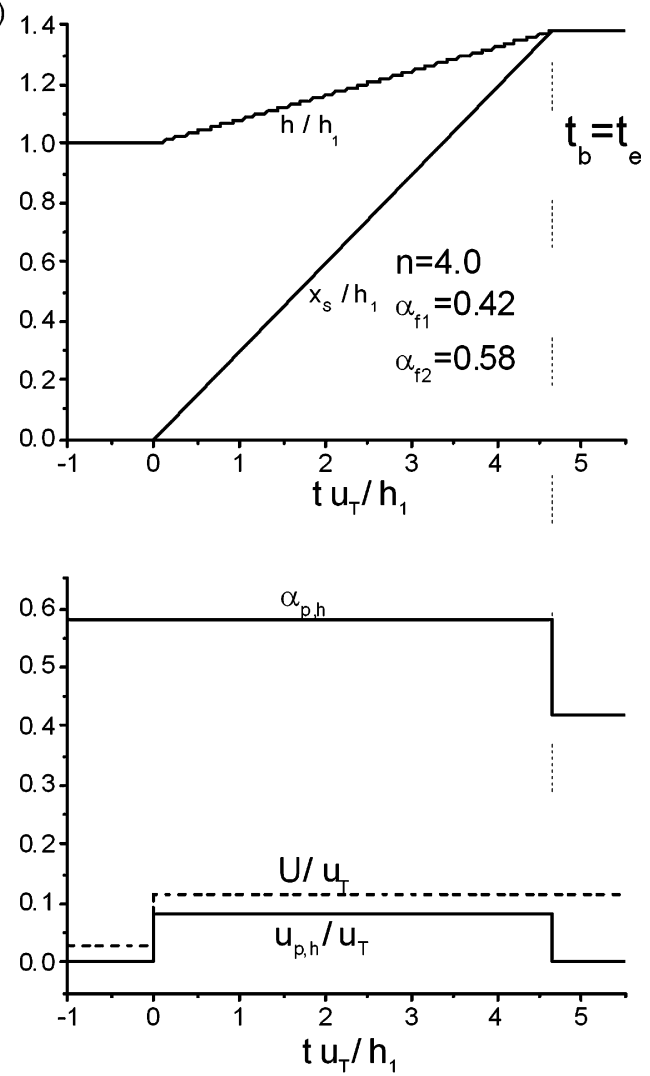

$\mathrm{h} / \mathrm{h}$

(c)
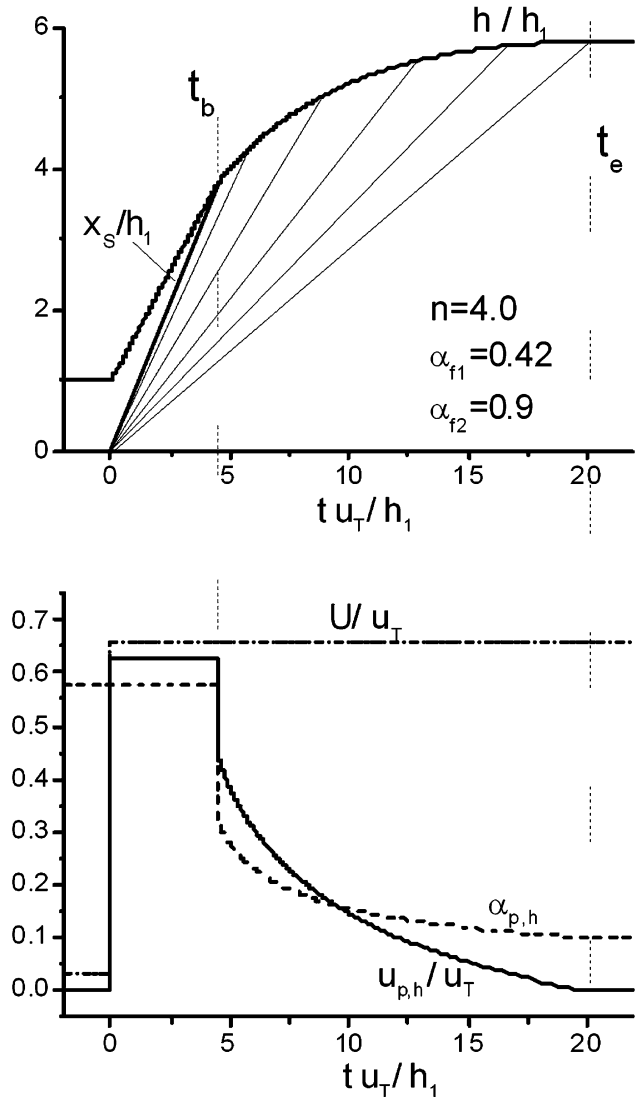

Fig. 5. Variation of solid phase velocity $u_{\mathrm{p}, \mathrm{h}}$ and concentration $\alpha_{\mathrm{p}, \mathrm{h}}$ at bed surface and bed height $h$ with elapsed time $t$ in expansion: (a) Region A; (b) Region B; (c) Region C. 
(a) 1
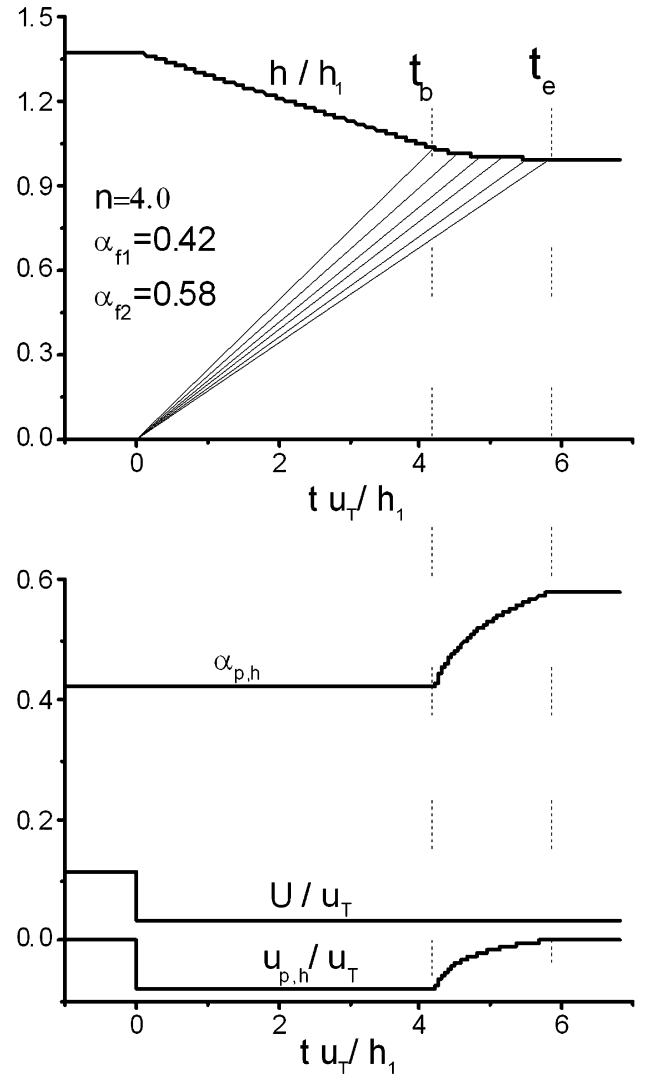

(b)
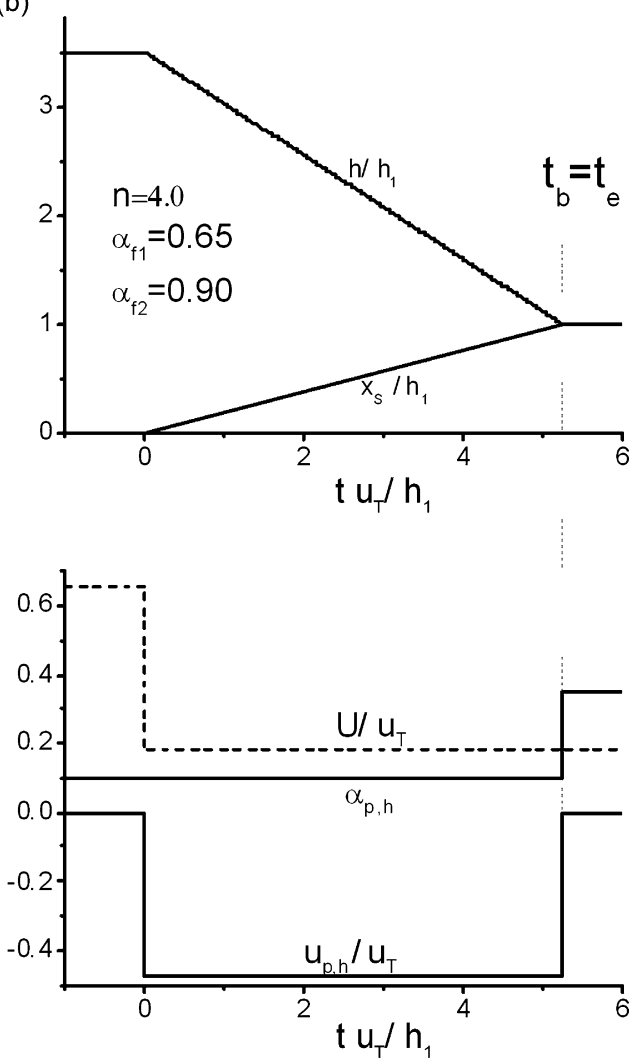

(c)
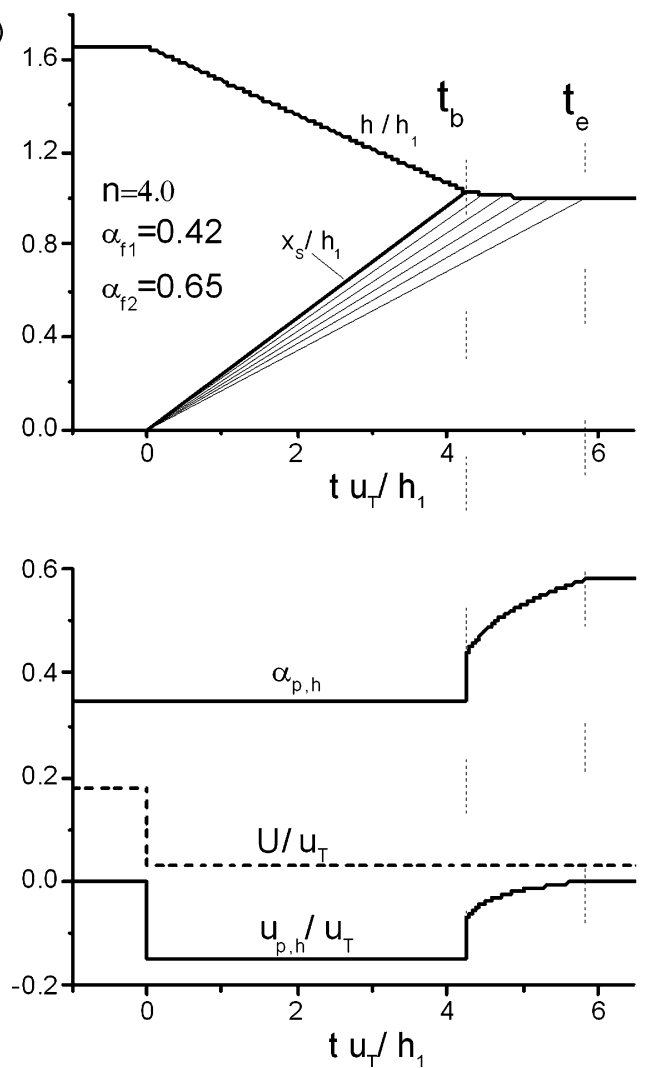

Fig. 6. Variation of solid phase velocity $u_{\mathrm{p}, \mathrm{h}}$ and concentration $\alpha_{\mathrm{p}, \mathrm{h}}$ at the bed surface and bed height $h$ with elapsed time $t$ in collapse: (a) Region B; (b) Region A; (c) Region $\mathrm{C}$ 
Table 1

Summary of expressions for $t_{\mathrm{b}}$ and $t_{\mathrm{e}}$ during expansion

\begin{tabular}{ll}
\hline Domain of $\alpha_{\mathrm{f} 1}$ and $\alpha_{\mathrm{f} 2}$ & Expressions for $t_{\mathrm{b}}$ and $t_{\mathrm{e}}$ \\
\hline Region B & $t_{\mathrm{b}}=t_{\mathrm{e}}=h_{2} / V_{\mathrm{S}}=\left[\left(\alpha_{\mathrm{f} 2}-\alpha_{\mathrm{f} 1}\right) h_{1} / u_{\mathrm{T}}\right] /\left[\left(1-\alpha_{\mathrm{f} 2}\right)\left(\alpha_{\mathrm{f} 2}^{n}-\alpha_{\mathrm{f} 1}^{n}\right)\right]$ \\
$\quad\left(1-\alpha_{\mathrm{p}, \mathrm{c}}\right)<\alpha_{\mathrm{f} 1}<\alpha_{\mathrm{f}, \mathrm{cr}}$ and $\alpha_{\mathrm{f} 1}<\alpha_{\mathrm{f} 2}<f\left(n, \alpha_{\mathrm{f} 1}\right)$ & \\
Region A & $t_{\mathrm{b}}=h_{1} /\left[V\left(\alpha_{\mathrm{f} 1}\right)-\left(U_{2}-U_{1}\right)\right]=\left(h_{1} / u_{\mathrm{T}}\right) /\left[n \alpha_{\mathrm{f} 1}^{n-1}\left(1-\alpha_{\mathrm{f} 1}\right)\right]$, \\
$\quad \alpha_{\mathrm{f}, \mathrm{cr}}<\alpha_{\mathrm{f} 2}<1$ and $\alpha_{\mathrm{f} 1}<\alpha_{\mathrm{f} 2}<1$ & $t_{\mathrm{e}}=h_{2} / V\left(\alpha_{\mathrm{f} 2}\right)=\left[\left(1-\alpha_{\mathrm{f} 1}\right) h_{1} / u_{\mathrm{T}}\right] /\left[n \alpha_{\mathrm{f} 2}^{n-1}\left(1-\alpha_{\mathrm{f} 2}\right)^{2}\right]$ \\
& \\
Region C & $t_{\mathrm{b}}=h_{1} /\left[V\left(\alpha_{\mathrm{f}, \mathrm{mid}}\right)-\left(U_{2}-U_{1}\right)\right]=\left(h_{1} / u_{\mathrm{T}}\right) /\left[\alpha_{\mathrm{f} 1}^{n}+n \alpha_{\mathrm{f}, \mathrm{mid}}^{n-1}-(n+1) \alpha_{\mathrm{f}, \mathrm{mid}}^{n}\right]$, \\
$\quad\left(1-\alpha_{\mathrm{p}, \mathrm{c}}\right)<\alpha_{\mathrm{f} 1}<\alpha_{\mathrm{f}, \mathrm{cr}}$ and $f\left(n, \alpha_{\mathrm{f} 1}\right)<\alpha_{\mathrm{f} 2}<1$ & $t_{\mathrm{e}}=h_{2} / V\left(\alpha_{\mathrm{f} 2}\right)=\left[\left(1-\alpha_{\mathrm{f} 1}\right) h_{1} / u_{\mathrm{T}}\right] /\left[n \alpha_{\mathrm{f} 2}^{n-1}\left(1-\alpha_{\mathrm{f} 2}\right)^{2}\right]$ \\
\hline
\end{tabular}

Table 2

Summary of expressions for $t_{\mathrm{b}}$ and $t_{\mathrm{e}}$ during collapse process

\begin{tabular}{ll}
\hline Domain of $\alpha_{\mathrm{f} 2}$ and $\alpha_{\mathrm{f} 1}$ & Expressions for $t_{\mathrm{b}}$ and $t_{\mathrm{e}}$ \\
\hline Region B & \\
$\quad \alpha_{\mathrm{f}, \mathrm{cr}}<\alpha_{\mathrm{f} 2}<1$ and $\max \left\{f\left(n, \alpha_{\mathrm{f} 2}\right),\left(1-\alpha_{\mathrm{p}, \mathrm{c}}\right)\right\}<\alpha_{\mathrm{f} 1}<\alpha_{\mathrm{f} 2}$ & $t_{\mathrm{b}}=t_{\mathrm{e}}=h_{1} / V_{\mathrm{S}}=\left[\left(\alpha_{\mathrm{f} 2}-\alpha_{\mathrm{f} 1}\right) h_{2} / u_{\mathrm{T}}\right] /\left[\left(1-\alpha_{\mathrm{f} 1}\right)\left(\alpha_{\mathrm{f} 2}^{\mathrm{n}}-\alpha_{\mathrm{f} 1}^{\mathrm{n}}\right)\right]$ \\
Region A & \\
$\quad\left(1-\alpha_{\mathrm{p}, \mathrm{c}}\right)<\alpha_{\mathrm{f} 2}<\alpha_{\mathrm{f}, \mathrm{cr}}$ and $\left(1-\alpha_{\mathrm{p}, \mathrm{c}}\right)<\alpha_{\mathrm{f} 1}<\alpha_{\mathrm{f} 2}$ & $t_{\mathrm{b}}=h_{2} /\left[V\left(\alpha_{\mathrm{f} 2}\right)+\left(U_{2}-U_{1}\right)\right]=\left(h_{2} / u_{\mathrm{T}}\right) /\left[n \alpha_{\mathrm{f} 2}^{n-1}\left(1-\alpha_{\mathrm{f} 2}\right)\right]$, \\
& $t_{\mathrm{e}}=h_{1} / V\left(\alpha_{\mathrm{f} 1}\right)=\left[\left(1-\alpha_{\mathrm{f} 2}\right)\left(h_{2} / u_{\mathrm{T}}\right)\right] /\left[n \alpha_{\mathrm{f} 1}^{n-1}\left(1-\alpha_{\mathrm{f} 1}\right)^{2}\right]$
\end{tabular}

force of the mixture equals $\Delta z(\pi / 4) D^{2}\left(\alpha_{\mathrm{f}} \rho_{\mathrm{f}}+\alpha_{\mathrm{p}} \rho_{\mathrm{p}}\right) g$ and the pressure drop is equal to $\Delta z(\pi / 4) D^{2} \mathrm{~d} p / \mathrm{d} z$.

In single-phase pipe flow with a given flow velocity $U$, the ratio of the drag force on sidewall to the gravity force increases quickly when the inner diameter of pipe $D$ decreases (the ratio is proportional to $D^{-2}$ ). However, it is completely different in fluidized bed. The drag force on sidewall is comparable with the gravity force under the condition that the voidage $\alpha_{\mathrm{f}}$ in bed, rather than the superficial velocity $U$, remains constant. For a given $\alpha_{\mathrm{f}}$, the superficial velocity $U$ is proportional to the particle settling velocity $u_{\mathrm{T}}$ (Richardson-Zaki expression) and $u_{\mathrm{T}}$ is approximately proportional to $\rho_{\mathrm{p}} d_{\mathrm{p}}^{2} g / \mu_{\mathrm{f}}$, so the superficial velocity $U$ and drag force on sidewall $F_{\mathrm{f}, \mathrm{w}}$ are proportional to $\rho_{\mathrm{p}} d_{\mathrm{p}}^{2} g / \mu_{\mathrm{f}}$ and $\Delta z \rho_{\mathrm{p}} d_{\mathrm{p}}^{2} g$, respectively. As a result, the ratio of drag force to gravity force is proportional to $d_{\mathrm{p}}^{2} / D^{2}$. Therefore the effect of the drag force on sidewall does not rise with the decrease of the diameter of column $D$ as long as the ratio $D^{2} / d_{\mathrm{p}}^{2}$ does not decrease. Actually, in Slis' experiments (Slis et al., 1959), $D=30 \mathrm{~mm}, d_{\mathrm{p}}=3 \mathrm{~mm}, D: d_{\mathrm{p}}=10$, and in Jin's experiments (Jin \& Liu, 2005), $D=30 \mathrm{~mm}, d_{\mathrm{p}}=1.8 \mathrm{~mm}, D: d_{\mathrm{p}}=16.6$. Their experiments showed that it was reasonable to ignore the drag force on the sidewall.

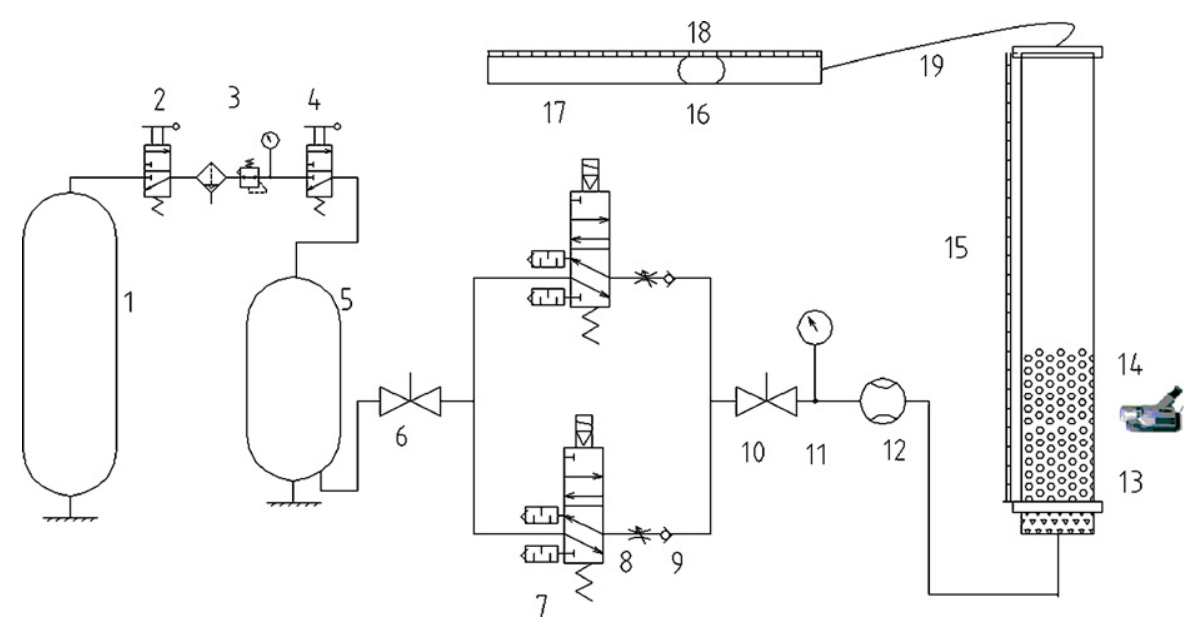

Fig. 7. Experimental setup for fine-particle fluidization: 1 , nitrogen cylinder; 2 , start valve; 3 , filter regulator; 4 , start valve; 5 , pressurized water reservoir; 6 , cut-off valve; 7 , solenoid valve; 8 , precision flow control valve; 9 , check valve; 10 , cut-off valve; 11 , pressure gauge; 12 , flowmeter; 13 , fluidized bed; 14, DV/DC; 15 , ruler; 16, air bubble; 17 , glass pipe; 18 , ruler; 19 , tube. 
Table 3

Properties of the materials used in experiments

\begin{tabular}{ll}
\hline$\rho_{\mathrm{p}}\left(\mathrm{kg} / \mathrm{m}^{3}\right)$ & $2.6 \times 10^{3}$ \\
$\rho_{\mathrm{f}}\left(\mathrm{kg} / \mathrm{m}^{3}\right)$ & $1.0 \times 10^{3}$ \\
$d_{\mathrm{p}}(\mathrm{mm})$ & 0.15 \\
$\alpha_{\mathrm{p}, \mathrm{c}}$ & 0.62 \\
$n$ & 4.00 \\
$u_{\mathrm{T}}(\mathrm{m} / \mathrm{s})$ & 0.0267 \\
\hline
\end{tabular}

\subsection{Experimental materials}

Glass beads were carefully sieved between two close meshes. The particle density $\rho_{\mathrm{p}}$ was determined pycnometrically with water. Properties of the materials used in experiments are listed in Table 3.

In order to determine the Richardson-Zaki exponent $n$ and particle setting velocity $u_{\mathrm{T}}$, we performed a set of steadystate experiments at different fluidizing velocities $U_{i}$, recording the corresponding bed height $h_{i}$ and calculating the corresponding voidage $\alpha_{\mathrm{f}, i}$ based on the particle conservative relationship $h_{0} \alpha_{\mathrm{p}, \mathrm{c}}=h_{i}\left(1-\alpha_{\mathrm{f}, i}\right)(i=1,2,3, \ldots)$, where $\alpha_{\mathrm{p}, \mathrm{c}}$ is the packed particle concentration and $h_{0}$ the bed height at the packed state. We fitted these data $\left(U_{i}\right.$ and $\left.\alpha_{\mathrm{f}, i}\right)$ against the Richardson-Zaki expression $U_{i}=u_{\mathrm{T}} \alpha_{\mathrm{f}, i}^{n}$ and got $n=4.00$ and $u_{\mathrm{T}}=0.0267 \mathrm{~m} / \mathrm{s}$ with a correlation coefficient of 0.9976 , as shown in Fig. 8. Results of steady-state experiments show that the Richardson-Zaki expression is also tenable for fine-particles in a narrow fluidized bed.

\subsection{Experimental results}

Several experimental evidences about the following two facts will be provided in this section to validate the theoretical analysis described above. First, when the parameter combination $\left(\alpha_{\mathrm{f} 1}\right.$, $\alpha_{\mathrm{f} 2}$ ) lies in region I in Fig. 2, the transient process of fine particles with larger Richardson-Zaki exponent $n$ behaves like that of larger particles with smaller $n$, that is, there is a transition zone of type A (a progressively broadening and upward-propagating continuous transition zone) between upper dense phase and lower dilute phase during bed expansion, and a transition zone

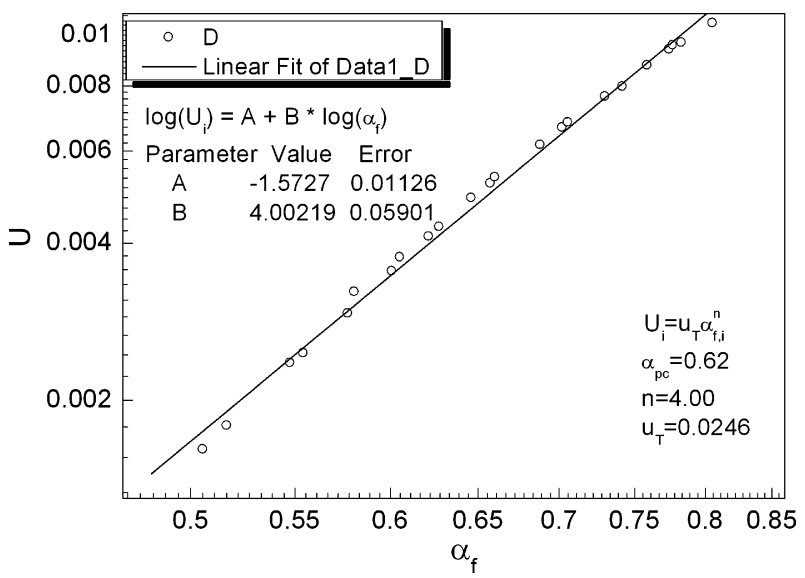

Fig. 8. Fitting experimental data on variation of voidage with fluidizing velocity. of type B (a concentration discontinuity) between upper dilute phase and lower dense phase during bed collapse. Second, under other conditions for fine particles, on the contrary, there is a transition zone of type B during bed expansion, and a transition zone of type A during bed collapse. Our primary interest was focused on the second fact.

A direct method to judge transition zone type is to observe (or measure) the zone width to see whether a concentration discontinuity exists or not. Another method is to observe the bed height curve $h(t)$ to see whether it is a smooth curve or has a sharp break.

The fine particles used in our experiments are the glass beads with diameter $d_{\mathrm{p}}=0.15 \mathrm{~mm}(n=4.0)$, and larger particles used in the control experiments are the glass beads with diameter $d_{\mathrm{p}}=1.8 \mathrm{~mm}(n=2.414)$.

Initially, a series of transient process experiments of fine particles were carried out in a fluidized bed with inner diameter $D=10 \mathrm{~mm}$, including expansion and collapse of type A and B, and using a camcorder to record the whole bed height variation, and the results were found in good agreement with the theoretical predictions, though, neither a concentration discontinuity in expansion of type B, nor a discontinuity in collapse of type B could be seen.

During experiments, we observe the concentration according to the intensity of the transmitted light. If there is an intensity discontinuity in the image, there will be a concentration discontinuity in the bed. But the light scattering caused by particles in bed may obscure the view of concentration discontinuity, or even make the blurred discontinuity disappear from the view. Light scattering is much stronger for fine particles than large ones for the same thickness of two-phase medium and same particle concentration. This may explain the phenomena that no concentration discontinuity was observed in transition zone of type B for fine particle collapsing, though the concentration discontinuity appears clearly when using larger particles under the same conditions. Following this clue, we conducted a series of experiments in beds with smaller inner diameters, $D=6 \mathrm{~mm}, 4 \mathrm{~mm}$ and $2.4 \mathrm{~mm}$, under the similar conditions. As the inner diameter decreased, the visibility of the concentration discontinuity was improved, and for $D=2.4 \mathrm{~mm}$, the concentration discontinuity became visible both in the collapse process of type B and in the expansion process of type $B$.

In all experiments, the bed was first maintained at a steadystate before a step change of fluidizing velocity was introduced. Under steady-state condition, the voidage throughout the bed is uniform. The bed experienced an expansion or collapse process upon a step increase of fluidizing velocity from $U_{1}$ to $U_{2}$ or a step decrease from $U_{2}$ to $U_{1}$ was introduced, respectively, where $U_{1}<U_{2}$. The results of the bed height and concentration discontinuity displacement prove a good agreement between the experimental data and model predictions, as shown in Figs. 9 and 10.

In the collapse process with the parameter combination $\left(\alpha_{\mathrm{f} 1}\right.$, $\alpha_{\mathrm{f} 2}$ ) falling into Region B (see Fig. 3(b)), we see a concentration discontinuity in the bed (see Fig. 11(b)) and the bed height curve $h(t)$ has a sharp break at $t=t_{\mathrm{b}} \approx 60 \mathrm{~s}$ (see Fig. 9(b)). In the expansion process with the parameter combination $\left(\alpha_{\mathrm{f} 1}, \alpha_{\mathrm{f} 2}\right)$ falling 

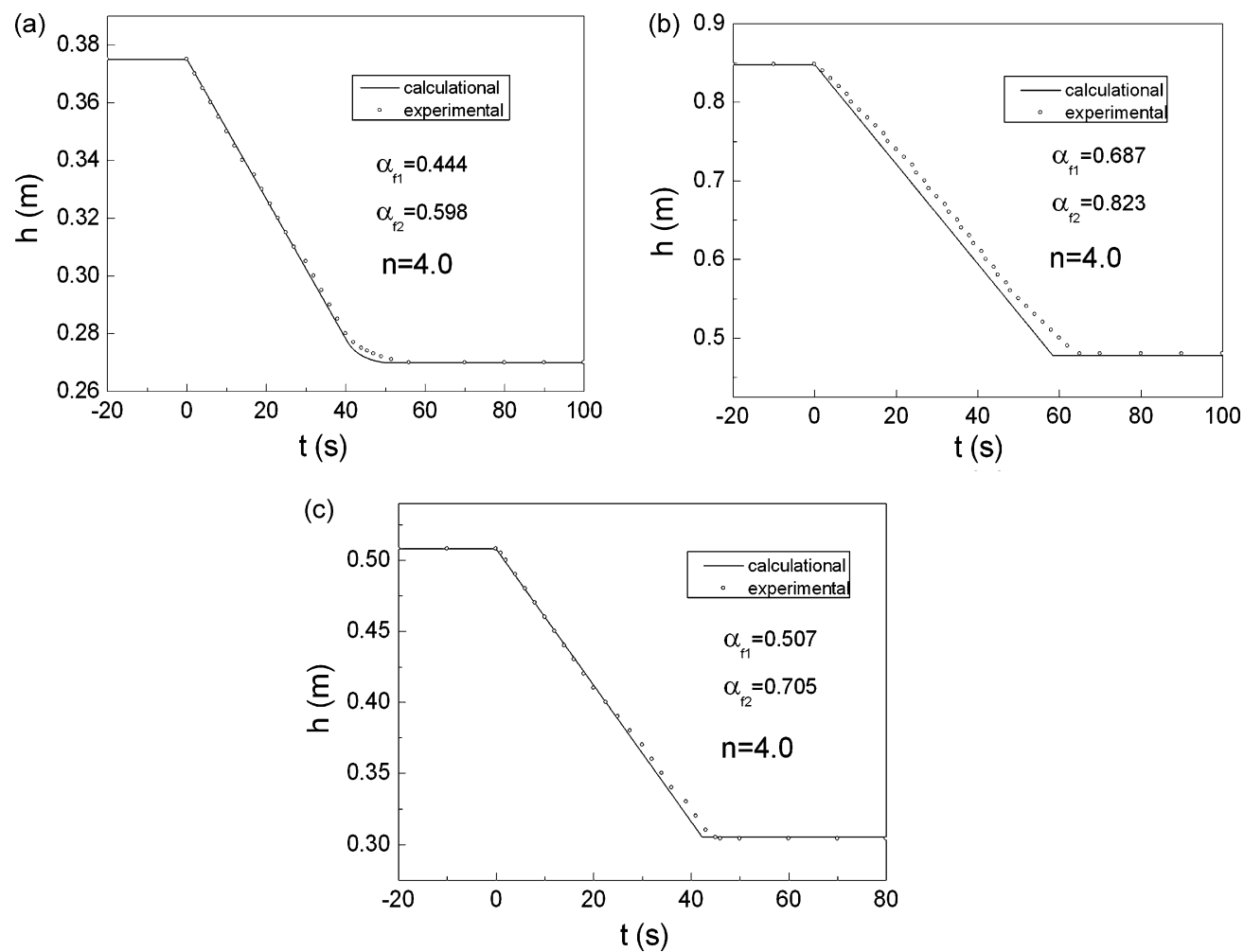

Fig. 9. Comparison between experiments and calculations of collapse processes in a fine particle fluidized bed: (a) $\alpha_{\mathrm{f} 1}$ and $\alpha_{\mathrm{f} 2}$ in Region A; (b) $\alpha_{\mathrm{f} 1}$ and $\alpha_{\mathrm{f} 2}$ in Region $\mathrm{B} ;$ (c) $\alpha_{\mathrm{f} 1}$ and $\alpha_{\mathrm{f} 2}$ in Region C.
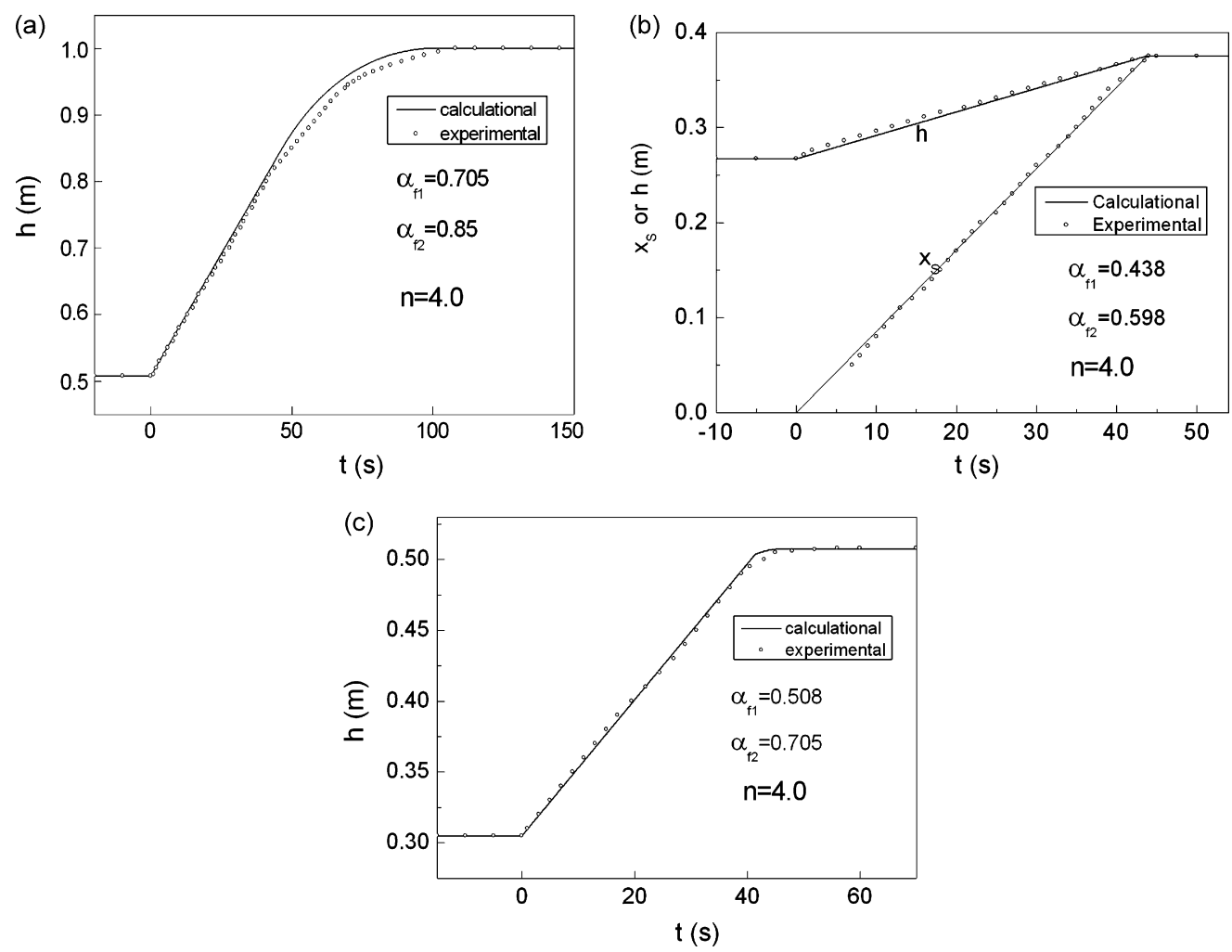

Fig. 10. Comparison between experiments and calculations of expansion processes in a fine particle fluidized bed: (a) $\alpha_{\mathrm{f} 1}$ and $\alpha_{\mathrm{f} 2}$ in Region A; (b) $\alpha_{\mathrm{f} 1}$ and $\alpha_{\mathrm{f} 2}$ in Region B; (c) $\alpha_{\mathrm{f} 1}$ and $\alpha_{\mathrm{f} 2}$ in Region C. 
(a)

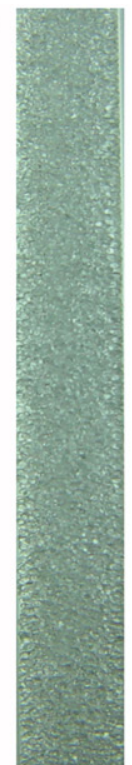

(A)

(b)

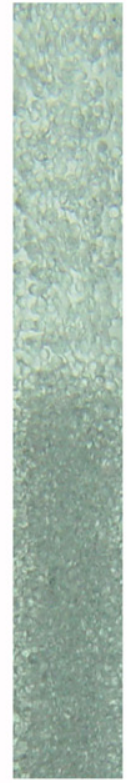

(A)

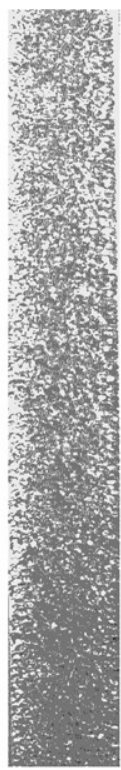

(B)

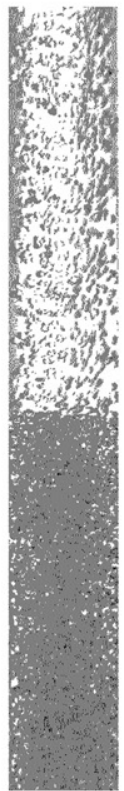

(B)

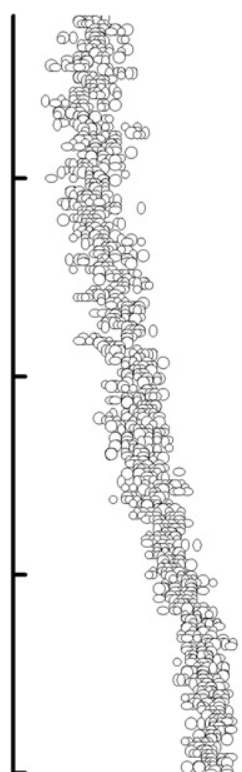

(C)

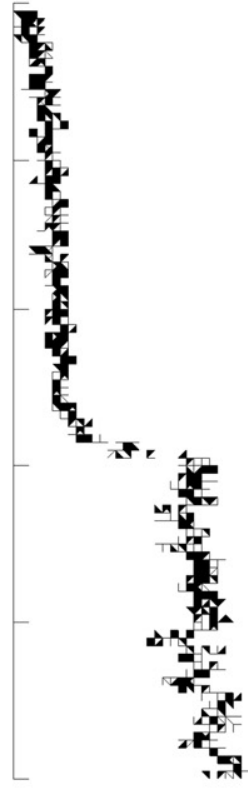

(C)
Fig. 11. Transient distribution of concentration during collapse process in a fine particle fluidized bed: (a) $\alpha_{\mathrm{f} 1}=0.42$ and $\alpha_{\mathrm{f} 2}=0.59$ in Region A; (b) $\alpha_{\mathrm{f} 1}=0.60$ and $\alpha_{\mathrm{f} 2}=0.83$ in Region B. Note: (A) a snapshot taken at an instant of bed collapse; (B) digitized grey scale chart; (C) grey value profile along the bed.

into Region A (see Fig. 3(a)), we see a transition zone in the bed where the concentration changes slowly (see Fig. 12(a)) and the bed height curve $h(t)$ is smooth (see Fig. 10(a)). These are the characteristics of collapse and expansion processes as we have already known.

In the collapse process with the parameter combination $\left(\alpha_{\mathrm{f} 1}\right.$, $\alpha_{\mathrm{f} 2}$ ) falling within Region A, we see a transition zone in the bed where the concentration changes slowly (see Fig. 11(a)) and the curve $h(t)$ is smooth (see Fig. 9(a)). In the expansion process with the parameter combination $\left(\alpha_{\mathrm{f} 1}, \alpha_{\mathrm{f} 2}\right)$ falling within (a)



(A)

(b)

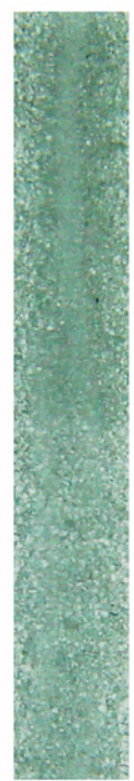

(A)

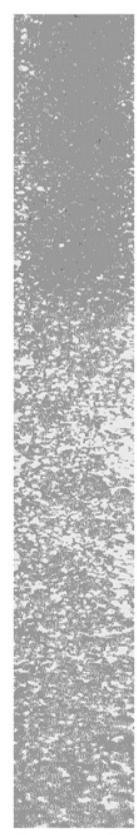

(B)

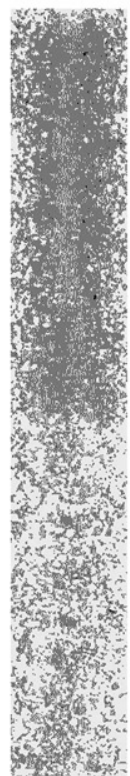

(B)

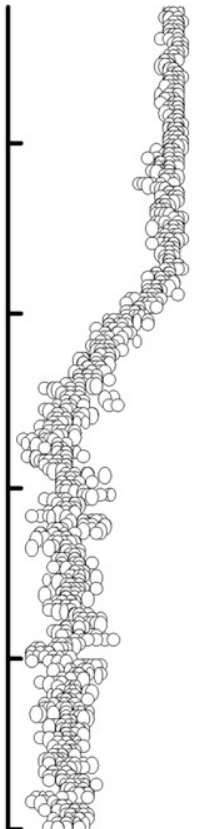

(C)

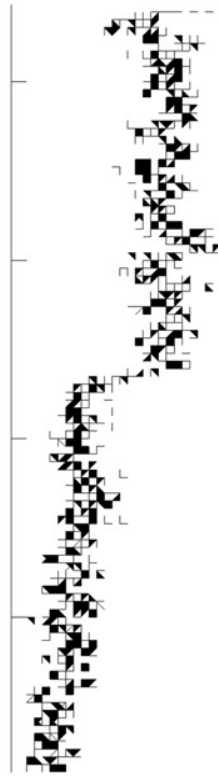

(C)

Fig. 12. Transient distribution of concentration during expansion process in a fine particle fluidized bed: (a) $\alpha_{\mathrm{f} 1}=0.62$ and $\alpha_{\mathrm{f} 2}=0.83$ in Region A; (b) $\alpha_{\mathrm{f} 1}=0.42$ and $\alpha_{\mathrm{f} 2}=0.59$ in Region B. Note: (A) a snapshot taken at an instant of bed expansion; (B) digitized grey scale chart; (C) grey value profile along the bed.

Region B, we see a concentration discontinuity in the bed (see Fig. 12(b)) and the curve $h(t)$ has a sharp break at $t=t_{\mathrm{b}} \approx 44 \mathrm{~s}$ (see Fig. 10(b)). Such transient characteristics of collapse and expansion have not been seen in the fluidized bed with larger particles.

If the parameter combination $\left(\alpha_{\mathrm{f} 1}, \alpha_{\mathrm{f} 2}\right)$ falls within Region $\mathrm{C}$ either in collapse process or in expansion process, the composition of the transition zone is complicated and we cannot record a fine and clear snapshot, however $h(t)$ data obtained in exper- 
iments agree well with the model predicted ones as shown in Figs. 9(c) and 10(c).

\section{Conclusions}

(1) Although bed expansion and collapse are converse processes, their transient phenomena are quite different due to the non-linear characteristic of Eq. (2), that is, the wave velocity $V$ is not constant but a function of voidage $\alpha_{\mathrm{f}}$. The voidage in the transition zone changes monotonically from the bottom up, thus resulting in chasing and interaction of waves. The function relation between $V$ and $\alpha_{\mathrm{f}}$ is dependent on the exponent $n$, and so both $V_{\max }$ and $\alpha_{\mathrm{f}, \mathrm{cr}}$, the voidage corresponding to the maximum wave velocity, are dependent only on the exponent $n$.

(2) If the parameters $\alpha_{\mathrm{f} 1}$ and $\alpha_{\mathrm{f} 2}$ in expansion or collapse processes fall into the range of $\alpha_{\mathrm{f}, \mathrm{cr}}<\alpha_{\mathrm{f} 1}<\alpha_{\mathrm{f} 2}$, we may see a concentration discontinuity propagating upward from the distributor when collapsing and a progressively broadening and upward-propagating continuous transition zone when expanding. These are the phenomena we have already known. This paper reveals theoretically that the contrary cases may occur for fine particles if the parameters $\alpha_{\mathrm{f} 1}$ and $\alpha_{\mathrm{f} 2}$ fall into the range of $\alpha_{\mathrm{f} 1}<\alpha_{\mathrm{f} 2}<\alpha_{\mathrm{f}, \mathrm{cr}}$. Our experiments have proved that, for fine particles with $0.15 \mathrm{~mm}$ diameter in a fluidized bed with inner diameter of $2.4 \mathrm{~mm}$, a concentration discontinuity may appear in an expansion process and a continuous transition zone may appear in a collapse process. If the parameters $\alpha_{\mathrm{f} 1}$ and $\alpha_{\mathrm{f} 2}$ fall into the range of $\alpha_{\mathrm{f} 1}<\alpha_{\mathrm{f}, \mathrm{cr}}<\alpha_{\mathrm{f} 2}$, we may see a concentration discontinuity followed by a succession of continuous waves in expansion process and in collapse process as well.

(3) As the basis of theoretical analysis in this paper, LEM model has proved capable of predicting dynamics in fluidized bed, meaning that it catches the essential aspects of two-phase flow in fluidized bed.
(4) Whether the effect of drag force on bed wall can be ignored in liquid-solid fluidization depends mainly on the ratio of bed diameter to particle diameter rather than the bed diameter itself. Bed height variations measured in the 2.4-mm-id bed with $0.15 \mathrm{~mm}$ diameter glass beads agreed well with the predictions of theoretical formula developed, in which the drag force effect on wall had been neglected.

\section{Acknowledgments}

This work is granted by the National Natural Science Foundation of China (NSFC No. 20376083) and Key Laboratory of Multiphase Reaction, Institute of Process Engineering, Chinese Academy of Sciences. The authors would like to thank Prof. H.Z. Sheng, for his suggestions of flux measurement.

\section{References}

Fan, L. T., Schmitz, J. A., \& Miller, E. N. (1963). Dynamics of liquid-solid fluidized bed expansion. AIChE Journal, 9(2), 149-153.

Jin, G. D. (2003). Numerical simulation of liquid pulsed fluidization and its experimental validation. Doctoral dissertation, Institute of Mechanics, Chinese Academy of Sciences, Beijing (in Chinese).

Jin, G. D., \& Liu, D. Y. (2005). Modeling and simulation of liquid pulsed particulate fluidized beds. Powder Technology, 154, 138-155.

Liu, D. Y., \& Jin, G. D. (2003). Modeling two-phase flow in pulsed fluidized beds. China Particuology, 1(3), 95-104.

Richardson, J. F., \& Zaki, W. N. (1954). Sedimentation and fluidization. Part 1. Transactions of the Institution of Chemical Engineers, 32, 35-53.

Slis, P. L., Willemse, T. W., \& Kramers, H. (1959). The response of the level of a liquid fluidized bed to a sudden change in the fluidizing velocity. Applied Scientific Research, Section A, 8, 209-218.

Thelen, T. V., \& Ramirez, W. F. (1997). Bed-height dynamics of expanded beds. Chemical Engineering Science, 52(19), 3333-3344.

Thelen, T. V., \& Ramirez, W. F. (1999). Modeling of solid-liquid fluidization in the Stokes flow regime using two-phase flow theory. AIChE Journal, 45(4), 708-723.

van der Wielen, L. A. M., Sjauw Koen Fa, A. W. K. G., Potters, J. J. M., \& Luyben, K. C. A. M. (1997). Transient behavior of pulsed particulate fluidized beds. AIChE Journal, 43(3), 625-630. 